\title{
Redefining the impact of nutrition on breast cancer incidence: is epigenetics involved?
}

\author{
Dorothy Teegarden ${ }^{1,2}$, Isabelle Romieu ${ }^{3}$ and Sophie A. Lelièvre ${ }^{2,4 *}$ \\ ${ }^{1}$ Department of Nutrition Sciences, Stone Hall, Purdue University, West Lafayette, IN, 47907-1264, USA \\ ${ }^{2}$ Oncological Sciences Center and Purdue University Center for Cancer Research, Purdue University, West Lafayette, \\ IN, 47907, USA \\ ${ }^{3}$ Nutrition and Metabolism Section, International Agency for Research on Cancer (IARC), 150 cours Albert Thomas, 69372, \\ Lyon cedex 08, France \\ ${ }^{4}$ Department of Basic Medical Sciences, Lynn Hall, Purdue University, West Lafayette, IN, 47907-2026, USA
}

\begin{abstract}
Breast cancer incidence is rising worldwide with an increase in aggressive neoplasias in young women. Possible factors involved include lifestyle changes, notably diet that is known to make an impact on gene transcription. However, among dietary factors, there is sufficient support for only greater body weight and alcohol consumption whereas numerous studies revealing an impact of specific diets and nutrients on breast cancer risk show conflicting results. Also, little information is available from middle- and low-income countries. The diversity of gene expression profiles found in breast cancers indicates that transcription control is critical for the outcome of the disease. This suggests the need for studies on nutrients that affect epigenetic mechanisms of transcription, such as DNA methylation and post-translational modifications of histones. In the present review, a new examination of the relationship between diet and breast cancer based on transcription control is proposed in light of epidemiological, animal and clinical studies. The mechanisms underlying the impact of diets on breast cancer development and factors that impede reaching clear conclusions are discussed. Understanding the interaction between nutrition and epigenetics (gene expression control via chromatin structure) is critical in light of the influence of diet during early stages of mammary gland development on breast cancer risk, suggesting a persistent effect on gene expression as shown by the influence of certain nutrients on DNA methylation. Successful development of breast cancer prevention strategies will require appropriate models, identification of biological markers for rapid assessment of preventive interventions, and coordinated worldwide research to discern the effects of diet.
\end{abstract}

Key words: Nutrition: Diet: Breast cancer: Epigenetics: Mammary gland

Triangular relationship: breast cancer incidence, gene transcription and nutrition

\section{Burden of breast cancer}

Globally an estimated 1.38 million new breast cancer cases were diagnosed in 2008, which represents $23 \%$ of all cancers $^{(1)}$. Breast cancer is the most common cancer in women from high-income countries and its frequency has been rising in low- and middle-income (LMI) countries. The range of incidence worldwide is great, with high rates (above 80 per 100000 ) in high-income regions of the world (with the exception of Japan) and low rates (less than 40 per 100000$)$ in most LMI regions. However, the mortality rate does not mirror that of incidence because of the more favourable survival from breast cancer in developed regions. Breast cancer ranks as the fifth cause of death from cancer overall (458000 deaths in 2008). Yet, breast cancer is the leading cause of mortality by cancer among women from LMI countries, which is in part related to poor access to screening, diagnosis and treatment ${ }^{(2,3)}$. The increase in incidence and mortality observed in LMI countries is thought to be due to a variety of factors such as population growth, ageing, lifestyle changes, and migration to urban communities ${ }^{(4,5)}$. Noticeably, it is a major public health concern that the incidence of breast cancer is rising among premenopausal women, with neoplasias more likely to display aggressive phenotypes and poor responses to therapy ${ }^{(5,6)}$.

Abbreviations: CPG, C-phosphate-G; ECM, extracellular matrix; ER, oestrogen receptor; IGF, insulin-like growth factor; LMI, low and middle income; miRNA, micro RNA; 1,25(OH) 2 D, 1,25-dihydroxyvitamin D; 25OHD, 25-hydroxyvitamin D; PR, progesterone receptor; RR, relative risk; VDR, vitamin D receptor; WCRF, World Cancer Research Fund.

*Corresponding author: Sophie A. Lelièvre, fax +1 765494 0781, email lelievre@purdue.edu 
The 20-year predictions for large increases in breast cancer incidence and mortality in LMI regions ${ }^{(1)}$ substantiate the urgency of the WHO's call for actions to support primary cancer prevention research and to develop effective strategies such as those that might be related to the environment, and particularly nutrition which has been reported to change along with breast cancer incidence ${ }^{(7)}$. A number of risk factors have been identified that could help explain breast cancer incidence in different countries and are listed in the WHO-International Agency for Research on Cancer cancer report ${ }^{(8)}$. Interestingly, a majority of risk factors are linked to nutrition (for example, obesity, alcohol consumption, birth weight, height, onset of puberty and menopause). As illustrated in the next sections, epidemiological, animal and clinical studies provide insights into the role of specific nutrients as well as dietary patterns in the development of breast cancer. However, a clear understanding of the impact of foods on the development of neoplasms requires scrutinising the mechanisms of action involved and timing during the lifespan of specific dietary intakes.

\section{Genomic impact of nutrition}

The growing research field referred to as nutrigenomics summarises it all: nutrition makes an impact on the genome to such a degree that it is paramount to understand this interaction in detail to prevent health disorders and help the treatment of diseases. Nutrigenomics may well unravel how genetic variations (for example, SNP) and epigenetic alterations (i.e. modifications at the gene level unrelated to changes in DNA sequence), which both control gene expression, influence the requirements for nutrients as well as the response to nutrients ${ }^{(8)}$. Such an understanding will be particularly important for several types of cancers that appear to be influenced by nutrition for their development, progression and/or recurrence ${ }^{(9)}$. Breast cancer is cited among these nutrition-dependent cancers mainly because of the risk brought by an overweight status in postmenopausal women and alcohol consumption. However, there is much to learn regarding the influence of foods on the mammary gland before and during breast cancer development according to a plethora of reports. Many nutrients have been described to have a potential impact on the mammary gland and its tumorigenesis in population and animal studies, but thus far there is little consensus revealed by meta-analyses ${ }^{(10)}$. Issues such as measurement error in nutritional assessment, the length of study and the timing of exposure may contribute to the discrepancy among studies that focus on nutrition and breast cancer. Another source of variation that is usually not taken into account is genomic diversity. Indeed, different forms of breast cancer can be identified through specific gene expression profiles which correspond to distinct disease outcomes and sensitivity to treatment ${ }^{(11)}$. Importantly, an emerging view is that the type or form of breast cancer is determined at the time of its onset $^{(12)}$, suggesting that genetic and environmental factors that play a role in tumour initiation might also influence how the disease will progress.

\section{Epigenetic regulation}

Gene expression profiles are closely controlled through epigenetic changes that can be defined as variations in the chromatin environment of a gene. These changes include the post-translational modification of histones (notably methylation and acetylation of lysines) and alterations in the degree of methylation of certain gene promoters by addition of methyl groups on the cytosines of C-phosphate-G (CpG) islands (cytosine and guanine connected by a phosphodiester bond (CpG) dinucleotide clusters) ${ }^{(13)}$. Such islands are currently defined as regions of DNA of more than $500 \mathrm{bp}$ with a $\mathrm{C}+\mathrm{G}$ content equal to or greater than $55 \%$ and observed $\mathrm{CpG}$ /expected $\mathrm{CpG}$ of $0.65^{(14)}$. DNA methylation influences the type of histone modifications that will be introduced at the gene promoter. Also, regardless of whether a promoter can be methylated it will be wrapped with histones bearing specific modifications. The type of histone modification will create epigenetic marks, and the specificity of these marks will lead to the recruitment of factors that either create a dense chromatin (for example, via the addition of heterochromatin protein, HP1) that prevents access to the DNA by the transcription machinery, hence leading to gene silencing, or favour the access to DNA by the transcription machinery notably via the displacement of histones by chromatin remodelling factors, hence leading to increased gene expression $^{(15)}$ (Fig. 1).

Depending on the location and the type of epigenetic modifications, the impact of these alterations on the expression of a particular gene will vary, ranging from silencing to full capacity expression. The complexity of epigenetic control is illustrated by the many possibilities to modify histones. For example, epigenetic marks can be found at defined lysines (for example, methylation on K4, K9, K27, K36, K79 on histone 3 and K20 on histone 4) of histones that participate either in gene expression or in gene repression and there exist different degrees of modifications for a given mark (for example, mono-, di- or trimethylation of lysines) ${ }^{(16)}$. Histone modifications are controlled by enzymes, such as methyltransferases, and protein complexes, such as polycomb complexes, for their chemical modifications. There are also proteins that sense histone modifications and further epigenetic changes at a gene promoter, like those involved in abnormal DNA hypermethylation characteristic of certain genes silenced in cancer ${ }^{(17)}$. The possibility of combining bivalent marks (i.e. the presence on the same gene promoter of histone modifications that favour transcription and histone modifications that repress transcription) is of extreme importance in stem 


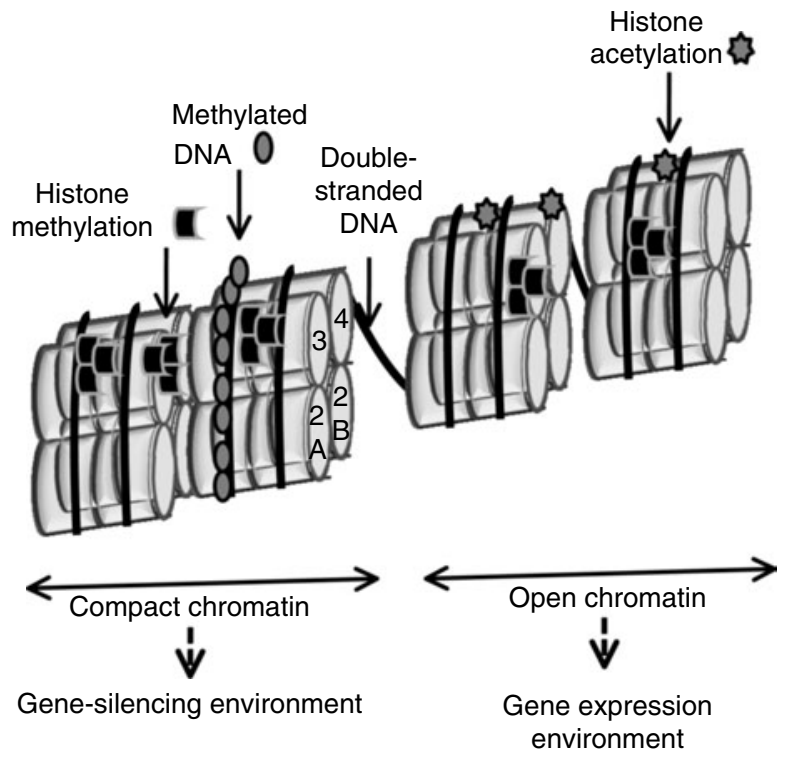

Fig. 1. Epigenetic mechanisms of gene transcription. An average of $147 \mathrm{bp}$ of double-stranded DNA (black thick line) are wrapped around histone octamers to form nucleosomes. Two sets of four distinct histones $(3,4,2 B$ and $2 \mathrm{~A}$ ) form the octamer. The loosening of DNA is obtained by triggering of histone modifications (for example, acetylation on lysine 12 of histone 4 and trimethylation on lysine 4 of histone 3 ) that leads to a decrease in the tightness of interactions among histones and between histones and DNA and, thus, an open chromatin stage amenable for transcription. Other histone modifications (for example, trimethylation of histone 3 on lysine 27 or on lysine 9) are conducive to gene silencing by compacting nucleosomes tightly. In certain gene promoters a stretch of DNA of several hundred bp enriched in C-phosphate-G $(\mathrm{CpG})$ islands could become methylated. This chemical modification has been considered as one of the sustainable changes leading to epigenetic inheritance through cell division and is found in a number of tumour-suppressor genes when cancer develops. Note: histone octamers are shown as blocks of eight light grey barrels, each barrel representing an individual histone. This is a simplified representation of chromatin organisation. The complex orientation of histones within the octamer and the histone 1 linker are not shown; the multiple protein complexes that are necessary to chemically modify histones and DNA (for example, with methylases, histone deacetylases) as well as those involved in histone displacement (for example, chromatin remodelling complexes) are not drawn.

cell populations ${ }^{(18)}$ since these cells are 'differentiation ready' with genes that can be rapidly expressed or repressed. Stem cells are present throughout the development of the mammary gland and suspected to be involved in breast cancer initiation.

About $70 \%$ of the human genome contains CpG islands (a stretch of 400 to $500 \mathrm{CpG}$ dinucleotides) and most of the remaining genes contain cytosines more randomly distributed that can also be methylated. While CpG island-poor genes can be silenced by DNA methylation, CPG islandrich genes can be silenced via histone modifications, without necessarily requiring these islands to be methylated, especially in normal tissues ${ }^{(18)}$. Yet, in cancer, CpG island-rich genes will often display DNA hypermethylation upon tumour development ${ }^{(19)}$. Since DNA methylation is considered to confer sustainable modifications in the epigenome $^{(20)}$, it will be critical to assess how foods might differentially have an impact on this epigenetic mechanism. Finally, a disconcerting observation is that the presence of a particular type of histone modification at a gene promoter is not sufficient to indicate whether a gene is silenced or not, with the exception of methylated H3K27, which is currently associated with repression of transcription $^{(21)}$. More generally, it is the combination of histones present that will determine the gene expression level. This outlines the possibility of fine-tuning for the control of gene transcription, but also renders epigenetic analysis difficult to interpret with current technologies.

The plasticity of epigenetic marks permits the establishment of the memory of past events in cells. Indeed, depending on the types of histone modifications, with or without association with the methylation of a promoter region, the silencing of a gene can be either stable or transient. The epigenetic environment of a particular gene may possibly be sustained over generations of cell divisions as well as generations of an individual, hence leading to long-term epigenetic memory. Therefore, when studying the effect of nutrition on the genome, there are two aspects to take into account. First, nutrients can make an impact on gene expression directly and their effect will be dependent on genetic variability (for example, SNP) as well as the cell type and status (for example, proliferation, degree of differentiation). Second, the transcriptional response to a particular nutrient can be different from one individual to another or even from one period to another in the life of an individual, depending on the cell's memory (i.e. the epigenome). The latter can be explained by the arrangement of different epigenetic modifications that contribute to the degree of chromatin compaction at gene loci, hence modulating the organisation of the cell nucleus at any given time. Such dynamic organisation of the cell nucleus acts as a soil that might respond or not to a given microenvironmental seed (for example, a nutrient) depending on the status of epigenetic modifications ${ }^{(12)}$.

To alleviate the burden of breast cancer that is affecting countries worldwide and is an urgent public health problem in many LMI countries, we must re-evaluate our approach to this disease to promote primary prevention. In light of the existing relationship triad of breast cancerepigenome-nutrition, the first part of the present review discusses how epigenetic studies have brought new insights into the origins of breast cancer. In the second part, we analyse the current status of the knowledge of the relationship between different groups of foods and breast cancer based on epidemiological, mechanistic and intervention studies. Whenever pertinent information is available, the impact of nutrition on breast cancer development via an effect on the epigenome is emphasised. Throughout the present review, necessary steps to develop strategies to prevent breast cancer are highlighted.

\section{Epigenetics and breast cancer}

It has long been known that breast cancer development is associated with modifications in the gene transcription 
profile. Since the discovery of tumour suppressors and oncogenes, and as a consequence of the development of genome-wide gene transcription analyses, a plethora of genes often involved in the regulation of cellular homeostasis (from proliferation to DNA repair and survival) has been implicated in the initiation and progression of cancer. In addition, the discovery of a variety of possible post-translational modifications of histones, the building blocks of chromatin, has shed new light on the mechanisms of gene transcription control and their importance in cancer. Efforts to prevent and treat neoplasias include epigenetic modifications to remodel the gene expression profile in cancer cells, with the goal notably to re-express tumour suppressors. Some success in the manipulation of the epigenome for treatment purposes is illustrated by US Food and Drug Administration approval to use agents that prevent DNA methylation in myeloma therapy; it has been followed by approval of the use of inhibitors of histone deacetylase for certain forms of lymphomas ${ }^{(22,23)}$. Targeting epigenetic mechanisms for therapy was initiated following results from a large body of studies indicating that preventing chromatin compaction by hypomethylating DNA and/or by inducing histone acetylation reduced cancer progression ${ }^{(22)}$. Beyond the global attack on the epigenome by such systemic therapies, epigenetic alterations offer the prospect of targeting the expression of specific genes since each gene that changes expression may show modifications in histones and possibly DNA methylation in its promoter region. As discussed in the following sections, cancer development appears to be accompanied by permanent epigenetic modifications, suggesting an involvement of mechanisms such as DNA methylation. The mammary gland is subjected to different phases of development from life in utero to menopause; therefore, an important question to answer for breast cancer is during what periods of the lifespan and by what factors epigenetic modifications are introduced which then alter the risk of developing cancers.

The concept of permanent or long-term epigenetic modifications is critical to understand as it has enormous consequences for determining the effect of modifiable factors, such as diet, on the breast tissue and the development of cancer prevention strategies. 'Permanent epigenetic modifications' means, for instance, that the repression of transcription of specific genes will be sustained even if the factors originally responsible for the repressive state are no longer present. However, it might be possible to change these epigenetic modifications either naturally with the appropriate signals or therapeutically, thus unlocking the repression status. As we will discuss, the fact that nutrients might be capable of inducing permanent epigenetic modifications could explain why diets and foods can have an effect on breast cancer risk that is shown many years after their consumption, and even in the offspring.

\section{Epigenetic modifications and breast cancer initiation}

In order to understand how nutrients could control breast cancer risk by influencing the epigenome, it is important to review current knowledge on the involvement of epigenetic changes in breast cancer development. There have been relatively few studies linking breast cancer risk factors and epigenetic alterations in genes involved in breast cancer. The paucity of information is linked to the fact that most studies have reported analyses done in tumour tissues and, thus, were focused on already developed cancers. There are, however, some interesting research avenues to clarify the role of epigenetic modifications in breast cancer development.

Logically, an active area of epigenetics research is to focus on tumour suppressors since these genes would have to be silenced to promote cancer development. BRCA1 is a gene involved in the onset of breast cancer and, if mutated, it increases the lifetime risk of breast cancer development by $45-85 \%{ }^{(24,25)}$. Interestingly, the breast tissue of women with BRCA1 mutations shows a different median DNA methylation index in a selected array of genes compared with non-BRCA1 mutation carriers, suggesting that a high breast cancer risk is associated with a different epigenetic pattern compared with women with an average risk ${ }^{(26)}$. Not surprisingly, BRCA1 has been found to be frequently hypermethylated in sporadic breast cancers ${ }^{(26)}$, indicating that even in the absence of mutation, epigenetic modifications linked to long-term silencing lead to shut-down of the expression of this important gene for breast cancer development. Another interesting area of investigation is the dysregulation of signalling pathways such as the complex wingless and integration site growth factor (Wnt) pathway that controls differentiation, proliferation and polarity. Negative regulators of the Wnt pathway, Wnt inhibitory factor-1 (WIF1) ${ }^{(27)}$ and Wnt inhibitor Dickkopf-3 $(D K K 3)^{(28)}$, display a hypermethylated promoter (conducive to gene silencing) in cancer. WIF1 methylation seems to be under the control of the DNA methyltransferases DNMT1 and DNMT3 $\beta$ that are associated with de novo methylation, especially in ageing cells $^{(27)}$. Other regulators of Wnt such as secreted frizzled-related protein 1 (SFRP1) and adenomatous polyposis coli $(A P C)$ have also been found to be methylated in breast cancer ${ }^{(29)}$. Thus, not only one element of a pathway, but also several up- and downstream components may be methylated on their gene promoter, ensuring the complete and sustained inactivation of that pathway.

In the breast, the status of the stroma (i.e. extracellular matrix (ECM), soluble factors and non-parenchymal cells present within the ECM) has been convincingly associated with the initiation and progression of cancers ${ }^{(30)}$. One of the current hypotheses is that fibroblasts, a major cellular compartment of the stroma involved in the making and modification of the ECM, are responsible for the modified stromal signalling that ultimately alters the epigenome of 
epithelial (parenchymal) cells ${ }^{(31)}$. Possible epigenetic modifications associated with early steps of breast tumorigenesis linked to the stroma include the hypermethylation of the TMS1 (target of methylation-induced silencing) gene promoter. TMS1 is involved in the control of ECM adhesion-dependent survival ${ }^{(32,33)}$. Unfortunately, examples of stroma-dependent changes in the epigenome of breast epithelial cells remain scarce. This field of research needs to be further developed in light of the influence that nutrients may have on the stroma by altering its exposure to hormones, promoting adiposity and triggering or reducing inflammatory pathways conducive to breast cancer development ${ }^{(34)}$.

Micro RNA (miRNA), the newly discovered class of RNA that control mRNA translation into proteins, have now been associated with breast cancer development. Not surprisingly, the promoters of genes coding for miRNA mir-9-1, mir-124a3, mir-148, mir-152, and mir-663 were found to be hypermethylated, in parallel to the hypermethylation of promoters of tumour suppressor genes, in primary breast cancers ${ }^{(35)}$. Thus, although miRNA are not part of epigenetic mechanisms of gene transcription (because they act downstream of chromatin), there is a strong epigenetic control of their expression upon cancer development that reinforces the direct epigenetic control observed for genes critical to prevent breast cancer development. The recent evidence that foods have an impact on miRNA expression ${ }^{(36)}$ expands the possibilities for nutrition to influence breast cancer risk via epigenetic effects.

If the transcription of key genes needs to change in order for a tumour to develop, it is important to identify the types of local epigenetic modifications involved. It is also important to know whether an epigenetic alteration is temporary or permanent for a given gene based on epigenetic marks, so that proper intervention strategies are designed. Ultimately, it should be possible to harness pathways critical for breast cancer prevention by linking the knowledge related to specific epigenetic alterations associated with breast tumour initiation and the identification of foods that have an impact on the breast tissue before the onset of tumour development.

\section{Effect of diet on epigenetic imprinting}

The possibility for epigenetic modifications to be passed through cell division and maintain the same expression level for specific genes can be referred to as imprinting. When epigenetic modifications occur in a parent and affect germ cells, they can be passed on to the next generation and propagated through cell division in the embryo. This particular phenomenon is known as 'genomic imprinting' and might be an explanation for why certain families display a high risk of developing cancer although no breast cancer susceptibility gene mutation has been identified. Also, if epigenetic modifications occur early in an individual's life and in a particular organ, it can affect a portion of the organ in which cells continue to divide, creating a specific field with high risk of developing breast cancer (for example, an entire ductal system or lobe within the breast). In addition, there is no reason why external factors could not also modify the epigenome of non-dividing cells in a particular organ, hence altering future responses of these cells to external signalling factors. The difference compared with the previous two scenarios is that epigenetic modifications in non-dividing cells should not be transmissible to other cells; hence, there would be long-lasting epigenetic memory in these cells but no transmission of epigenetic marks to the next generation of these cells. Therefore, regardless of the stage of the mammary gland, necessary environmental factors such as foods are likely to exert profound epigenetic effects, with propagation of sustained epigenetic modifications likely when they occur during the three major development phases (fetal development, puberty, pregnancy) (Fig. 2). In the paragraphs below we give examples of how dietary intakes could differentially make an impact on cancer development depending on when during the lifespan a particular diet is followed.

Fetal programming, a period during which the methylation of genes will be modified by the parental profiles or exposure in utero, is a high-risk stage for abnormal derepression of imprinted genes. Indeed, following fertilisation the parental genomes undergo demethylation before de novo methylation. This period has been described as placing an individual at increased risk of developing diseases as a result of intra-uterine constraint ${ }^{(37)}$. If proper methylation did not occur during embryogenesis, certain genes might become expressed and lead to enhanced risk of cancer development, such as when the gene for the stimulation of proliferation of insulin-like growth factor (IGF)-2 becomes demethylated. Food components that make an impact on IGF-2 notably include soya isoflavones as described later in the present review.

A clear correlation between early impact of diet and cancer development has been obtained with animal models. Rats receiving higher levels of the micronutrient choline in utero compared with controls showed reduced tumour growth and longer survival. The effects on the genome included higher expression of genes associated with favourable prognosis for breast cancer and decreased expression of certain genes associated with unfavourable prognosis compared with the control group (i.e. with deficient choline supplementation during gestation) ${ }^{(38)}$.

The risk of developing diseases can continue for generations, such as in families with high incidence of breast cancer without a known breast cancer susceptibility gene mutation. On the other hand, the effect of exposure to certain risk factors for breast cancer later in life might be transient and disappear upon removal of the risk factor and mainly depend on the continuous presence of the implicated factors ${ }^{(39)}$. Examples of this include hormone 


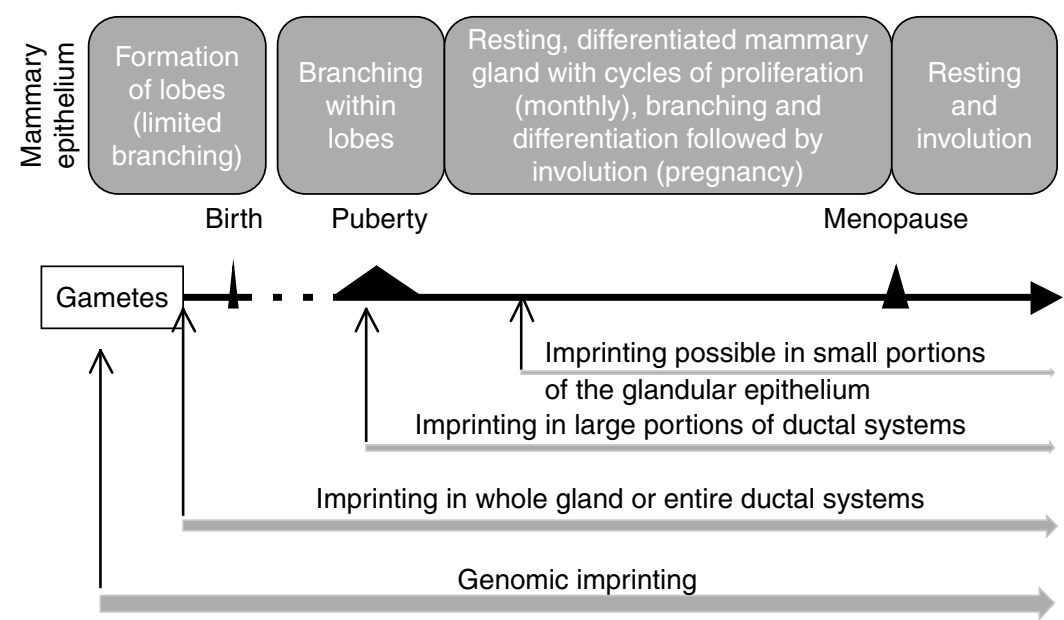

Fig. 2. Possible impact of epigenetic modifications upon dietary influence during the lifespan of the mammary gland. There is still much to be understood regarding human breast development and a lot of information is extrapolated from studies in rodents. The human mammary gland evolves constantly with the formation, on average, of twelve individual ductal systems or lobes with limited branching of ducts with blunt-ended ductal termini during fetal development. Considerable secondary branching and elongation of the ductal systems and formation of terminal ductal lobular units (TDLU) occur upon hormonal stimulation during puberty, and lobes further branch out to develop into lactating tissue followed by involution of part of the glandular tissue during pregnancy/lactation cycles. All the phases of development will encompass TDLU (these structures are present in the majority starting at puberty and until menopause), thus affecting areas of the breast where cancers develop. Therefore, epigenetic alterations occurring at different periods during the lifespan of an individual might affect the mammary gland to various extents based on the possibility to propagate permanent/long-term epigenetic marks through cell division (see grey arrows). The period between birth and puberty is not accompanied by extensive breast development; instead, it is proposed to comprise an involution phase shortly after birth and slow growth that accompanies the body's growth afterwards; this period is represented by the dashed line on the drawing (periods of times between life events are not represented to scale). Menopause is characterised by a reduction in the number of TDLU and ducts ${ }^{(280)}$.

replacement therapy, although the effects are still debated and may also be protective ${ }^{(40)}$, and hormonal contraception. Although several explanations exist for the duration of the 'risk factor effect' after the agent inducing the risk is gone, one possibility that we introduced earlier may be the existence of 'permanent' (or long-term) and temporary modifications in the epigenome. Indeed, it is currently accepted that epigenetic alterations that involve DNA methylation can be sustained ${ }^{(41)}$. Therefore dietary risk and protective factors that specifically make an impact on DNA methylation might be more readily associated with long-term effects.

The increasingly recognised impact of foods on the epigenome warrants exploration of whether diets or specific dietary components can contribute to epigenetic modifications associated with breast cancer development. Components of foods, including dietary fats and amino acids, have been reported to have an effect on mammary gland development ${ }^{(42-44)}$. Even though the impact of nutrition on epigenetics in the breast tissue remains largely unexplored $^{(45)}$, preliminary work reveals that nutrients associated with variations in breast cancer risk can indeed have an effect on the epigenome.

\section{Diet and breast cancer}

The large body of literature on nutrition and breast cancer has been recently reviewed and summarised by an international panel gathered by the World Cancer Research Fund (WCRF) ${ }^{(46)}$. In reviewing the literature, it is important to consider a number of issues related to study design, model systems and interpretation of studies. These issues, along with scarce information on the interaction of the epigenome with the response to nutrients, lead to difficulty in understanding the impact of nutrients on breast cancer risk. First, the results of epidemiological studies need to be interpreted with caution, as they do not determine cause and effect. The size of the study, the lack of diversity in dietary habits analysed in each study, the measurement error in outcome variables, and individual variation in human genetics and lifestyle factors may limit the ability to measure the probably very small size effects due to diet. Human models used in epidemiological studies have the caveat that most cancers develop over a relatively long period of time and, thus, interventions related to primary prevention, i.e. to inhibit the development of abnormal tissue growth, cannot be determined in epidemiological studies or clinical trials as the length is not sufficient or the relevant window of exposure is not captured in the intervention trial to assess true prevention. Another important issue is the level of nutrients compared in studies pertaining to breast cancer risk. If this level is in the severely deficient range it might have multiple effects on the organism and breast cancer development might be a secondary consequence of the deficiency.

\section{Advantages and limitations of study designs}

Clinical trials investigating the impact of diet on breast cancer prevention are limited. There are a number of issues contributing to such paucity. As explained previously, studying cancer prevention requires lengthy trial 
periods as breast cancer generally takes years to develop and is influenced by critical periods in breast epithelial tissue growth, i.e. fetal development, adolescence and pregnancy. It has been suggested that the diet during adolescence is an important predisposing factor for breast cancer risk later in life ${ }^{(47,48)}$. Thus, nutritional exposures during pregnancy ${ }^{(49)}$ as well as during fetal development and adolescence alter breast cancer risk ${ }^{(50)}$. The comparison of risks across a broad range of dietary patterns as well as specific periods of life has not been thoroughly studied. In addition, a large number of participants is required to achieve a reasonable amount of cases for statistical analysis in randomised trials of undiagnosed subjects. Also, previous studies demonstrate that the selection of 'at-risk' populations does not represent cancer prevention because this population may be more likely to have already developed cancer ${ }^{(51)}$. The effects of diets may also vary based on race, menopausal status, tumour characterisation (oestrogen receptor (ER)-positive $(\mathrm{ER}+)$ or ER-negative (ER-)) and weight or BMI, and these factors are not always considered in the analysis or the interpretation of the results. Finally, it is difficult to maintain compliance to dietary regimens for long periods of time. Therefore it will be critical to identify biomarkers for very early signs of breast cancer development that can be utilised to rapidly determine the impact of environmental factors on breast cancer risk and the success of actions proposed to reduce breast cancer incidence.

Animal models offer advantages because of genetic similarities and better control of environmental influences, including diet. However, animal models used to study cancer prevention often lack relevance to human breast cancer development. Rodent models provide opportunities for genetic manipulation that bring important information about the molecular mechanisms that underlie cancer progression and environmental interventions. Unfortunately, results are not consistently reproducible in human trials. Cell-based studies also contribute significantly to our understanding of the molecular mechanisms of dietary components to alter specific cellular processes essential to breast tumour development. However, the breast epithelial cell models most commonly used are cancer cells and, thus, they do not mimic stages of human breast cancer initiation. Even if some cell lines represent early stages in the development of breast cancer, rarely are they utilised in a physiologically relevant manner since most studies use traditional cell monolayer cultures that lack tissue morphogenesis and, thus, do not reproduce the three-dimensional tissue architecture known to direct the expression of genes involved in normal differentiation ${ }^{(52)}$.

However, the use of animal and cell models is critical to the overall determination of the impact of diet on breast cancer progression because these models contribute to determining mechanisms. Animal studies provide information that could not be obtained with human populations, particularly because it is difficult to assess diet in epidemiological studies and to achieve and maintain prescribed diets in intervention studies, and because the impact of diet may be specific to early exposure (prenatal to adolescence) which requires extended intervention periods. In rodent models cancer is generally experimentally induced (usually by means of a chemical carcinogen or irradiation), leading to the generation of tumours in all the animals in a relatively short period of time, thereby reducing the number of animals and time, i.e. cost required. However, there are no adequate models of cancer prevention that are easily translatable to humans and results must be considered with caution. Similarly, in vitro cell model systems often used to decipher the mechanisms of action of nutrients lack the physiological relevance to breast cancer development. Nevertheless, both animal and cell models, in spite of their limitations, can bring important insights into the role played by foods in breast cancer development.

Therefore, it is important to consider the cumulative results from each of these imperfect model systems to garner sufficient information in reviewing and establishing firm conclusions on how foods might make an impact on the breast. To simplify the review of the literature presented in the next paragraphs, whenever applicable, the results from the different models are subdivided into specific diet/foods categories. Within these categories the role of diet in modifying breast cancer risk and the proposed underlying mechanisms and potential roles of the interaction of diet and the epigenome are discussed.

\section{Obesity}

Epidemiological studies. There is substantial support for obesity increasing the risk of a variety of cancers, including breast cancer. The WCRF review panel concluded that weight is one of the few factors that convincingly leads to an increase in breast cancer risk in postmenopausal women $^{(46)}$. Measures of weight are generally BMI $\left(\mathrm{kg} / \mathrm{m}^{2}\right)$, waist and hip circumferences, or waist:hip ratio. These assessments are not only indirect measures of increased adiposity, but they also provide information about body fat distribution. An analysis of cohort studies suggests that in postmenopausal women, the smallest waist circumference lowers breast cancer risk compared with the largest waist circumference and that there is a $24 \%$ lower risk in women with the smallest waist:hip ratio ${ }^{(53)}$. However, further evidence suggests that the impact of obesity may be modified by race, as the relationship between BMI and breast cancer risk was noted in white but not African-American postmenopausal women ${ }^{(54)}$.

In contrast to the increased risk of breast cancer with obesity in postmenopausal women are reports that increased weight may protect premenopausal women from breast cancer. For example, the higher the BMI at 18 years of age, the lower the risk in premenopausal women in the overweight to obese category (BMI $\geq 25 \mathrm{~kg} / \mathrm{m}^{2}$ ) 
compared with a low BMI $\left(<20 \mathrm{~kg} / \mathrm{m}^{2}\right) \quad($ OR 0.76 ; $95 \%$ CI $0.63,0.90)^{(54)}$. Moreover, a BMI of $\geq 35 \mathrm{~kg} / \mathrm{m}^{2}$ (morbidly obese) compared with normal to low weight BMI of $<25 \mathrm{~kg} / \mathrm{m}^{2}$ is accompanied by a reduced breast cancer risk (OR 0.81; 95\% CI 0.61, 1.06) in premenopausal women. Neither of these associations with breast cancer risk is modified by race ${ }^{(37)}$. Thus, obesity makes an impact on the risk of breast cancer positively and negatively, depending on the menopausal status (or age).

The association between obesity and breast cancer risk may be, at least in part, dependent on tumour type. For example, waist and hip circumferences and waist:hip ratio were significantly associated with a $1.95-$ to 2.75 fold increased risk only for ER- breast cancer development in the Nurses' Health Study II $(n 45799)^{(55)}$. Also, high $\left(\geq 35 \mathrm{~kg} / \mathrm{m}^{2}\right)$ BMI was associated with increased risk of $\mathrm{ER}-$ and progesterone receptor (PR)-positive $(\mathrm{PR}+)$ tumours among postmenopausal African-American women compared with normal to low BMI $\left(<25 \mathrm{~kg} / \mathrm{m}^{2}\right)$, with an OR of $1.83(95 \% \text { CI } 1.08,3.09)^{(54)}$.

Intervention studies to determine the impact of increasing weight on breast cancer are not feasible, but the impact of reducing or gaining weight has been explored. Increasing weight loss in women who reached their highest adult weight at younger ages ( $<45$ years), but not older ages, was associated with a reduced risk of postmenopausal breast cancer (OR 0.9; 95\% CI 0.84, 0.95 per $5 \mathrm{~kg})^{(56)}$. Further, reducing adiposity appeared to reduce the risk for breast cancer ${ }^{(57,58)}$. When weight gain was calculated from the lowest adult weight, greater weight gain modestly increased risk by $8 \%$ for each $5 \mathrm{~kg}$ of gain (OR 1.08; 95\% CI 1.06, 1.11). Thus, epidemiological studies support that modification of weight can alter breast cancer risk.

Epidemiological studies also provided evidence that adiposity during pregnancy influences adiposity in the offspring, which might have consequences for breast cancer risk in the next generation ${ }^{(59)}$. For example, the strongest predictor of being in the upper tertile of weight and percentage body fat in children (8.8 (SD 1.8) years) followed prospectively from birth was a maternal BMI of $>30 \mathrm{~kg} / \mathrm{m}^{2}(\mathrm{OR} 3.75(95 \%$ CI $1.39,10 \cdot 10)$ and OR 5.45 $(95 \%$ CI $1.62,18.41)$, respectively $)^{(60)}$. In a cross-sectional study, the BMI of children (5-7 years, $n$ 3306) correlated with parental BMI, with the strongest association with maternal BMI (OR 2.9 for boys, 3.2 for girls) ${ }^{(61)}$. These results suggest that either maternal BMI during pregnancy may have a long-term impact on children's weight gain, or that environmental influences when parents have a high BMI may affect the BMI of their offspring. In addition, a recent pooled analysis including approximately 22000 breast cancer cases shows that birth weight was positively associated with breast cancer risk in studies based on birth records (pooled relative risk (RR) per $1 \mathrm{SD}(0.5 \mathrm{~kg})$ increment in birth weight: 1.06 ; $95 \%$ CI 1.02, 1.09) and parental recall when the participants were children (1.02;
$95 \%$ CI 0.99, 1.05). However, studies based on adult selfreports or maternal recall during the women's adulthood $(0.98 ; 95 \%$ CI $0.95,1.01)$ did not report significant effects $(P \text { for heterogeneity between data sources } 0.003)^{(62)}$. Birth length and head circumference from birth records were also positively associated with breast cancer risk (pooled RR per 1 SD increment: 1.06 (95\% CI 1.03, 1.10) and 1.09 (95\% CI 1.03, 1.15), respectively). These data emphasise the importance of recording birth weight and other birth anthropometric measures in a standardised manner to avoid misclassification related to recall.

The influence of maternal intake on adiposity in the offspring has also been investigated by studying the weight and BMI of monozygotic and dizygotic twins. Some of these studies suggested that height (which is a risk factor for breast cancer) and weight, but not BMI are influenced by the intra-uterine environment ${ }^{(63)}$, although birth weight predicted higher BMI in other twin studies ${ }^{(64,65)}$. Therefore, the epidemiological evidence to support a relationship between maternal BMI during pregnancy and the risk for obesity in the offspring, which confers a risk for breast cancer later in life, is suggestive but not definitive.

In summary, observational population studies suggest that breast cancer risk is increased in postmenopausal women with high BMI, waist circumference and waist:hip ratio. However, higher BMI may confer protection against breast cancer in premenopausal women. The distribution of the adiposity (central $v$. overall) may also influence the risk in addition to menopausal status and race. Finally, evidence supports that there may be a relationship between maternal BMI and offspring, but further evidence is required to clarify these relationships. Most interestingly, the fact that weight gain might be associated with a specific type of breast tumour suggests a link with determinants of breast cancer types, such as gene expression profile, which emphasises the need to study the relationship between obesity and epigenetics.

\section{Animal models}

It is particularly important to use animal models for nutrients or other lifestyle factors, such as obesity, that will not be tested for their impact in human trials because they lead to increased risk for diseases. It is now recognised that adipose tissue is not only a storage entity for excess energy in the form of TAG, but also functions as a source of hormones that could affect breast tissue homeostasis. Examples are found in the serum levels of the adipose tissue hormones leptin and adiponectin, which are positively and negatively, respectively, correlated with adiposity. These hormones are being explored as potential mediators or protectors of the development of breast cancer. In addition, obesity induces a state of chronic inflammation and greater adiposity is associated with insulin resistance and diabetes, which may play roles in the well-characterised relationship between obesity and 
increased risk of several cancers, including breast cancer. Importantly, dietary energy restriction protects against the development of mammary tumours in mice, regardless of the energy nutrient limited in the study ${ }^{(66)}$. Determining if there is a relationship between obesity and breast cancer risk is complicated, as obesity is associated with high-fat diets, and models of obesity have often employed high-fat diets to increase energy density and induce greater adiposity, complicating the interpretation of experimental results. Therefore, studies related to obesity are confounded by the interaction of obesity with high-fat diets and health consequences, such as diabetes, which makes it difficult to decipher the role, and related specific mechanisms, of obesity in the development of breast cancer.

\section{Mechanisms}

The mechanisms, explored thus far, by which obesity may increase breast cancer risk are diverse ${ }^{(67,68)}$. Adiponectin, which is inversely related to fat mass, inhibits cell proliferation and suppresses angiogenesis ${ }^{(69-71)}$ and inflammation ${ }^{(72,73)}$. Adiponectin levels are lower in the presence of breast cancer compared with controls in both pre- and postmenopausal women. Furthermore, tumours of women in the lowest tertile of serum adiponectin are larger and of higher grade compared with tumours of women in the other tertiles ${ }^{(74)}$. In contrast, leptin, the serum levels of which are positively related to fat mass, may promote breast cancer progression ${ }^{(70)}$. The ratio of serum levels of leptin to adiponectin may also be important ${ }^{(75-77)}$. Other adipokines such as vascular endothelial growth factor, hepatocyte growth factor and heparin-binding epidermal growth factor-like growth factor also promote angiogenesis ${ }^{(78)}$ and, hence, could participate in breast cancer development.

Other well-studied mechanisms that might be associated with breast cancer development include factors involved in insulin resistance and diabetes, which are consequences of increased adiposity. Insulin promotes cell proliferation and increased uptake of energy substrates for cell proliferation. Consequently, high serum insulin levels that occur in insulin resistance and type 2 diabetes are suggested to play a role in the development of breast cancer. Indeed, a two-fold increase in breast cancer risk was noted in the highest tertile of serum baseline insulin levels compared with the lowest tertile in postmenopausal women ${ }^{(79)}$. Furthermore, studies in animals showed that the insulin receptor and IGF receptor played a role in mammary carcinogenesis in a non-obese model of type 2 diabetes ${ }^{(80)}$. Insulin sensitivity may also be controlled by the adipokines ${ }^{(81)}$, further confounding the relationships between insulin and obesity. Inflammatory mediators, such as $\mathrm{TNF} \alpha$ associated with high adiposity $^{(82)}$, may also play a role in promoting tumour development ${ }^{(67)}$. Therefore, both animal models and strong mechanistic-based studies support that adipokines, insulin and inflammatory mediators may underlie the relationship between obesity and breast cancer ${ }^{(67)}$ although the specific mediator(s) are not yet clearly defined.

It is particularly important to note that some of these mediators might also be involved in the impact that maternal obesity may have on the offspring to increase their propensity of not only being overweight but also of developing mammary tumours. The well-known consequences of obesity proposed to increase the risk of breast cancer in adults may also alter the risk of the offspring for obesity ${ }^{(83)}$. For example, offspring of female mice fed an obesogenic diet (40\% energy safflower-seed oil) during pregnancy had an increased mammary tumour incidence following chemical induction ${ }^{(84)}$. Maternal overnutrition led to increased adipogenic, lipogenic and adipokine gene expression in fetal adipose tissue $^{(83)}$ and maternal high-fat diet during pregnancy and lactation altered hepatic expression of IGF-2 and key microRNA in the adult offspring ${ }^{(85)}$. Conversely, undernutrition during pregnancy was associated with increased risk for obesity and hyperphagia in the offspring ${ }^{(86)}$, which may confer increased risk for breast cancer. Several studies have shown that if the fetus were exposed to maternal diabetes, a frequent consequence of obesity, there would be increased obesity in the offspring ${ }^{(87)}$.

\section{Epigenetics}

There is a critical need for research in epigenetics related to obesity and breast cancer development. A compelling study demonstrated an effect of dietary methyl supplementation, which is used in methylation pathways, during the fetal period in preventing the development of obesity through generations of agouti mice ${ }^{(88)}$. Unfortunately, mammary tumour development was not assessed in this study. Another study using male Wistar rats showed that a highfat diet was capable of methylating CpG sites at the leptin promoter and was associated with a reduction of the level of circulating leptin in rats that became obese ${ }^{(89)}$.

It has been emphasised by others that it will be particularly important to focus on life in utero in light of the relationship of fetal growth with obesity and breast cancer $^{(90)}$. Notably, the review of studies on birth weight and breast cancer risk by Michels \& Xue ${ }^{(91)}$ pointed to the loss of imprinting of IGF-2 and high expression level of this stimulator of breast epithelial cell proliferation in women with high birth weight. However, the mechanism by which IGF-2 expression is epigenetically altered remains to be deciphered.

In conclusion, there is substantial evidence in animal and human models to support an impact of obesity on breast cancer. Clearly, dietary patterns such as macronutrient intake including alcohol, high-fat diet and carbohydrates, insulin sensitivity as well as micronutrients influence the development and maintenance of an obese status. Thus, the bearing of obesity on breast cancer risk may be due to the obese state and/or the dietary effect 
on obesity. There are multiple potential mechanisms that may mediate breast cancer risk associated with obesity and determining which mechanism is predominant will be a challenge. An important aspect to investigate is the potential epigenetic component of the risk brought by obesity, suggested by the impact of maternal exposures on the risk for the offspring to develop breast cancer.

\section{Relationship of dietary patterns: healthy or Western?}

A body of literature has focused on determining the relationship between dietary patterns and breast cancer development. Dietary patterns are comprised of a variety of dietary components that are prevalent in specific diets. Dietary components may function individually or in combination within the food matrix, hence increasing their impact. Generally, the dietary patterns investigated are a prudent or healthy dietary pattern (high in vegetables and/or fruits, poultry, fish, low-fat dairy products and/or whole grains) as compared with the Western diet or socalled unhealthy diet (red or processed meats, refined grains, sweets and/or high-fat dairy products). The results of epidemiological studies are inconsistent, with a variety of reports supporting that dietary patterns with fruit and vegetable intake ${ }^{(87,92,93)}$ or high-fibre-low-fat intake ${ }^{(94)}$ are inversely associated with breast cancer risk when comparing lowest to highest intake while other reports find no association $^{(95-98)}$.

\section{Epidemiological studies}

In a review of the literature by the WCRF, the evidence was not convincing that a healthy diet conferred protection from breast cancer ${ }^{(46)}$. Consistent with this review, results of the large European Prospective Investigation into Cancer and Nutrition (EPIC) study ( $n>360000$ women) demonstrated no relationship between breast cancer incidence and fruits and vegetable intake ${ }^{(99,100)}$. Contrasting results for a prudent/healthy diet were shown in a subsequent meta-analysis completed with strict inclusion criteria. From the sixteen studies used, it was concluded that a prudent/healthy dietary pattern conferred a reduced risk of breast cancer in the highest intake compared with the lowest intake categories, with an OR of $0.89(95 \%$ CI $0.82,0.99 ; P=0.02$ ), whereas a similar comparison of high and low categories in the Western/unhealthy dietary intake groups showed no difference ${ }^{(101)}$. Still, a pooled analysis from eight prospective studies found no significant association either between vegetable intake and breast cancer or between fruit and breast cancer ${ }^{(102)}$. In some cases, specific components of fruit and vegetable intake, such as dark yellow-orange vegetables (comparing lowest and highest quintile of intake; OR 0.79; $95 \%$ CI $0.60,0.98$ ), dark green vegetables (comparing lowest and highest quintile of intake; OR $0.65 ; 95 \%$ CI 0.51 , $0 \cdot 83)^{(92)}$ and raw vegetables (comparing $\geq 67.4 \mathrm{~g} / \mathrm{d}$ with
$<67.4 \mathrm{~g} / \mathrm{d}$; OR 0.63; $95 \%$ CI 0.43, 0.93) $)^{(93)}$ were associated with reduced risk of breast cancer.

Reasons for the discrepancy between study results may be found in other lifestyle factors that will influence breast cancer risk or interact with the dietary pattern. For example, in one study, lower risk was associated with a healthy dietary pattern with BMI less than $25 \mathrm{~kg} / \mathrm{m}^{2103}$, but there was no association when BMI was $\geq 25 \mathrm{~kg} / \mathrm{m}^{2}$. Moreover, dietbreast cancer risk associations may be influenced by energy intake ${ }^{(104)}$, and age and menopausal status ${ }^{(99,100)}$. Interestingly, other examples suggest that an association between breast cancer risk and healthy/prudent diet may depend on the tumour type, such as ER and PR positive or negative tumours ${ }^{(105)}$. For example, a fruit and vegetable intake is associated with an increased risk of developing ER + tumours, but a decreased risk of developing ER-tumours ${ }^{(106,107)}$. Furthermore, the effect of a healthy diet to decrease breast cancer risk is strengthened with ER $+/$ PR- tumours ${ }^{(104)}$. Results of studies with a Western diet are also inconsistent, with reported positive association $^{(108,109)}$, negative association ${ }^{(110,111)}$ or no association with breast cancer risk ${ }^{(95,97,98,103)}$. Similar to 'healthy diets', the unhealthy dietary pattern associations with breast cancer risk may be dependent on other factors, such as menopausal status ${ }^{(110)}, \mathrm{BMI}^{(112)}$ and tumour types ${ }^{(87,113)}$.

The divergence in results described here is potentially due to differences in the definition of the dietary patterns, the absence of careful control over confounding factors and the small number of cases after stratification by specific breast cancer characteristics. Moreover, as discussed in the present review, it may also be related to the epigenetic characteristics of the populations studied.

\section{Animal models}

Generally, animal studies indicate that diets rich in fruits and vegetables, including cruciferous vegetables, protect against mammary tumour development ${ }^{(114)}$. Because of the complexity of the nutrients and non-nutritional components in the diet, several underlying mechanisms have been suggested to prevent mammary tumours including antioxidant capability, protection against DNA damage, detoxification of carcinogens, and inhibition of specific cellular pathways that control proliferation, apoptosis and angiogenesis. Animal studies are strengthened by cell culture-based studies showing that specific components of these diets, such as isothiocyanates, which are capable of inhibiting histone deacetylase and thus could have an epigenetic effect ${ }^{(115)}$, and indoles found in cruciferous vegetables, can limit cellular pathways characteristic of tumour progression. The discrepancy between animal studies showing a positive impact of diets rich in fruits and vegetables to inhibit mammary tumours, and the epidemiological studies showing mixed results, is potentially based on the limitations discussed above for population studies (i.e. the ability to measure dietary intake, 
the interaction with other lifestyle factors, the genetic and epigenetic make-up (or status), and the timing of exposure).

\section{Intervention trials}

The Women's Health Initiative is a randomised dietary intervention study in which postmenopausal women were counselled to reduce dietary fat intake and increase consumption of fruits and vegetables ( $n 48$ 835), with an average $8 \cdot 1$-year follow-up period ${ }^{(116)}$. Overall, there was a small (9\%), non-significant reduced risk for invasive breast cancer in the intervention group compared with the control group ${ }^{(116)}$. The intervention reduced the incidence of invasive breast cancer only in women with a high fat intake at baseline and the risk was significantly reduced only for PR- tumours and independent of ER status. In a randomised controlled multi-site (thirty-nine centres) intervention trial ( $n$ 2437) in women following early-stage breast cancer, lower fat intake (and thus energy intake) was accompanied with a $24 \%$ reduction in recurrence risk, with an even greater impact on women with ER- cancer ( $42 \%$ lower risk). Another randomised control trial to reduce fat intake and increase carbohydrate intake in which women were followed for 10 years had no effect of fat intake, but there was an increased risk of ER + breast cancer with lower carbohydrate intake ${ }^{(117)}$. However, the limitations of these trials in terms of a true link to dietary fats include maintenance of compliance to the intervention, inability to decipher confounding factors such as obesity and energy intake and the time or period of exposure. Indeed, regarding the latter, the intervention may be far later than when diet may be most effective in protecting the breast, such as during fetal development and adolescence. It is also important to note that this particular trial was focused on breast cancer recurrence, which might not be comparable with intervention studies on women who have never had breast cancer as the breast tissue will have undergone treatments and possible tumour field effects (i.e. modifications in normal tissues induced by paracrine and other microenvironmental effects from an adjacent cancer).

\section{Epigenetic studies}

There are few studies in this area and the ones that exist focus either on the impact of specific dietary patterns on epigenetic marks globally or on very specific organs excluding the breast. A study relating a vegetarian lifestyle and DNA methylation did not reveal any significant association $^{(118)}$. In contrast, preliminary reports from animal studies indicated an effect of prenatal protein-restricted diet on the methylation of specific $\mathrm{CpG}$ dinucleotides in the PPAR $\alpha$ gene promoter in the liver ${ }^{(119)}$. Studies such as this reveal the profound impact that maternal diet has on epigenetic make-up in the offspring and sets the course for susceptibility to certain diseases ${ }^{(120)}$.

\section{Soya intake}

Epidemiological studies. Overall, there is a significant record of research studies on the impact of soya intake on breast cancer. Generally, epidemiological studies suggest that higher soya isoflavone intakes are associated with lower breast cancer risk, though not all are supportive ${ }^{(121-123)}$. For example, in Asian populations where soya consumption is high, the incidence of breast cancer was found to be lower than in other cultures with low soya intake levels ${ }^{(124)}$. Daughters of Asian women who immigrated to countries with Western cultures have had a higher risk of developing breast cancer than either their mothers or their grandmothers ${ }^{(125)}$. A meta-analysis that included eighteen studies suggested that soya intake was inversely associated with breast cancer risk in women from the West, particularly in premenopausal women, but not in women from Asia ${ }^{(126)}$. However, the results of another meta-analysis supported that women from the West (with low soya intake ranging from 0.8 to $0.15 \mathrm{mg}$ soya isoflavone per d) were not protected by greater soya intake; however, Asian women, including both Asian and Asian-American women, had a reduced breast cancer risk if they increased soya intake (comparing the lowest level of soya intake $\leq 5 \mathrm{mg} / \mathrm{d}$, OR $0 \cdot 71,95 \%$ CI $0 \cdot 60,0.85$ and intake $\geq 20 \mathrm{mg}$ isoflavone/d $)^{(121)}$. Therefore, the results of the epidemiological studies investigating the relationship between soya intake and breast cancer risk remain controversial.

Interestingly, a number of studies have investigated the relationship between soya intake during childhood and adolescence and the risk of breast cancer development later in life. In a case-control study by Korde et $a l .{ }^{(127)}$ employing 966 controls and 597 cases selected among Asian-American women, childhood, adolescent and adult intakes were associated with a significantly reduced breast cancer risk among women who consumed the highest level of soya, with intakes during childhood showing the strongest and most consistent relationship with breast cancer risk (OR 0.40; $95 \%$ CI $0 \cdot 18,0.83$ ). These results are similar to other case-control studies which provide further evidence to support the importance of soya intake during adolescence as they showed that adolescent soya intake was inversely associated with breast cancer risk $^{(128)}$ in both pre- and postmenopausal women ${ }^{(129)}$. A recent meta-analysis including fourteen studies revealed that soya isoflavone intake was associated with a significant reduction of breast cancer risk in Asian populations (OR 0.76; 95\% CI 0.65, 0.86) but not in Western populations (OR $0.76 ; 95 \% \mathrm{CI} 0 \cdot 87,1 \cdot 06)^{(130)}$. Thus, the results of epidemiological studies relating soya intake to breast cancer risk are not clear, and the impact may depend on genetics/epigenetics, prior soya intake, timing of exposure and level of soya intake. 


\section{Animal and cell models}

A variety of studies in animal models with chemically induced cancer showed that soya proteins reduced mammary tumour incidence ${ }^{(131-139)}$. The active component proposed to mediate the effect on breast cancer is genistein, a metabolic product of soya, which is structurally very similar to oestradiol and activates $\alpha$ - and $\beta$-ER. Genistein is shown to prevent mammary tumours in animal models $^{(131-136,139)}$, including xenograft models $^{(140)}$, although results are contradictory ${ }^{(141)}$. Soya protein intake does not alter characteristics of mammary epithelial tissue that are associated with breast cancer risk, including proliferation, epithelial area and apoptosis, in premenopausal female monkeys ${ }^{(142)}$. Similar to epidemiological studies, results with animal studies support that soya and genistein may reduce tumour progression in premenopausal mouse models ${ }^{(33,34)}$. However, soya and genistein promote tumorigenesis in postmenopausal rodent models ${ }^{(35,36)}$. These observations suggest a link between oestrogen pathways and the effect of soya. An added level of potential variability for the effect of soya is shown by the fact that chemoprevention by genistein in carcinogen-induced mammary cancer in rats is dependent on the diet matrix ${ }^{(143)}$.

A number of mechanisms have been proposed to explain the action of genistein on tumorigenicity. As mentioned above, one of the more studied mechanisms is through oestrogen-dependent pathways, as there is substantial evidence that genistein has oestrogenic activity. However, other mechanisms may play a role, as soya intake in adulthood does not influence oestrogenic effects in non-human primates ${ }^{(142)}$. Other possible mechanisms of the impact of genistein on breast tumorigenesis include inhibition of epidermal growth factor receptor tyrosine kinase activity and of topoisomerase II activity, antioxidant properties, regulation of eicosanoid metabolism, and cellspecific effects such as cell cycle progression arrest, induction of apoptosis, and inhibition of angiogenesis ${ }^{(144-146)}$.

\section{Clinical trials}

There are a number of randomised clinical intervention trials for soya or isoflavones in which mammographic density was used as a marker for breast cancer risk. A meta-analysis of eight randomised controlled isoflavone intervention trials which extended from 6 months to 3 years suggested that there was no overall effect of dietary isoflavones on breast density, although isoflavone intervention led to a small increase in mammographic density in premenopausal women ${ }^{(147)}$. Because of the potential for oestrogenic activity, it is of particular concern that soya isoflavones may increase the risk of breast cancer in postmenopausal women, in particular for the development of ER + tumours. A randomised clinical 2-year isoflavone supplementation trial in 358 postmenopausal women showed no modification of breast density ${ }^{(148)}$ Other 1-year ${ }^{(149)}$ and 3-year ${ }^{(150)}$ randomised clinical trials in postmenopausal women also showed no effect. Similarly, a 2-year soya intervention trial in premenopausal women did not change mammographic density ${ }^{(151)}$. Overall, clinical trials do not support an impact of soya on breast density; however, there is still too little information from intervention trials to determine the impact of soya specifically on breast cancer development.

\section{Epigenetic studies}

In regards to epigenetics, there is much to learn from soya and related compounds. As for other nutrients, the modulation of gene expression, notably that controlled by oestrogen, occurring upon exposure to soya suggests that epigenetics-mediated effects might be involved in alterations in breast cancer risk. Furthermore, the effects of soya may differ given the time of exposure and have a long-lasting impact on the offspring. For example, exposure during pregnancy to oestrogen or genistein in rodents increases the risk of mammary cancer among the offspring ${ }^{(152-154)}$. In contrast, results suggest that prepubertal genistein exposure may increase differentiation of the mammary ductal system ${ }^{(64)}$, resulting in reduced breast cancer risk ${ }^{(98)}$.

One possible molecular mechanism of soya action is through the Wnt/ $\beta$-catenin signalling pathway that regulates progenitor cells. Indeed, overactivity of this pathway leads to excessive mammary out-growth ${ }^{(29)}$. As Wnt/ $\beta$-catenin is one of the pathways affected by genistein/soya, early-life exposure to soya may affect later breast cancer risk by influencing the differentiation and, thus, the epigenome of progenitor cells proposed to be involved in mammary tumour development ${ }^{(155)}$. The hypothesis of a strong epigenetic impact of soya is supported by a study in which maternal exposure to genistein increased methylation of six cytosine-guanine sites upstream of the transcription start site of the Agouti gene in yellow Agouti mice ${ }^{(156)}$, enhancing the number of Agouti offspring that exhibited the pseudo agouti phenotype linked to lowered cancer risk. Genistein exposure also negated the DNA hypomethylating effect of an endocrine disruptor, bisphenol $\mathrm{A}^{(157)}$.

The few studies that have focused on the impact of foods on the epigenome in human subjects are quite revealing when investigating soya isoflavones. Work conducted with breast cancer-free premenopausal women using cells acquired by ductal lavage showed a correlation between soya isoflavone intake over one menstrual cycle and the induction of dose-specific modifications in the methylation of promoters of proliferation regulatory genes (RARß2 (retinoic acid receptor $\beta 2$ ) and CCND2 (cyclin D2)) associated with breast cancer development $^{(158)}$. The fact that other genes analysed showed no significant epigenetic alteration suggests that the type of 
foods might have a selective epigenetic effect, and/or that in this particular and relatively homogeneous population of women, the other genes were not receptive to epigenetic modifications possibly due to the status of the mammary gland. In any case, real progress in understanding how foods might have an impact on breast cancer risk requires the identification of all specific genes that might be epigenetically modified. Additional candidate genes include cell cycle checkpoint gene p16, implicated in breast cancer development and the promoter of which might be differentially methylated depending on genistein. Noteworthy, RAR $\beta$ and p16 are also influenced by dietary factors such as folic acid and resveratrol ${ }^{(158,159)}$. Moreover, soya isoflavone ingested by premenopausal women has been associated with increased methylation of genes coding for IGF-2 and cyclin G2 in mammary epithelial cells ${ }^{(158)}$. Thus, soya-related compounds could possibly prevent the expression of a number of genes associated with cell proliferation.

\section{Macronutrients}

Alcohol: epidemiological studies. The only dietary factor identified by the WCRF analysis for which there was convincing evidence for its association with increased breast cancer risk beside obesity in postmenopausal women is alcohol intake ${ }^{(46)}$. An overwhelming number of epidemiological studies, including the Women's Health Initiative ${ }^{(160)}$, have provided support for the positive relationship between alcohol, including wine, and breast cancer risk $^{(46,161-166)}$. An intake of two or more alcoholic drinks per $\mathrm{d}$ for the past 5 years confers about an $82 \%$ increase in risk compared with no alcohol consumption ${ }^{(167)}$. Another estimate is that each additional $10 \mathrm{~g}$ alcohol per $\mathrm{d}$ increases the risk of breast cancer approximately by $10 \%$ based on two meta-analyses ${ }^{(168,169)}$. According to the European Prospective Investigation into Cancer and Nutrition (EPIC) study, a 3\% increase in risk is associated with $10 \mathrm{~g} / \mathrm{d}$ of recent alcohol intake ${ }^{(170)}$. However, like for the results related to dietary patterns and obesity, the relationship may be modified as a function of the tumour type since breast cancer risk is associated with alcohol in $\mathrm{ER}+$ tumours $^{(104,171)}$

\section{Alcohol: mechanisms}

The mechanism underlying the relationship between alcohol consumption and breast cancer risk has not been clearly defined $^{(172-174)}$. However, the action of alcohol consumption on breast cancer risk might be linked to the induction of endogenous oestrogen levels. For example, consumption of approximately one to two alcoholic drinks per d increases oestrogen levels in premenopausal and postmenopausal women ${ }^{(175,176)}$. Moreover, a metabolite of alcohol, acetaldehyde, has genotoxic action that may contribute to the development of cancer $^{(172,174)}$.
Alcohol is also a solvent, notably for tobacco carcinogens, and may allow greater permeability of carcinogens across cell membranes ${ }^{(172)}$. Alcohol has also been proposed to modulate enzymes involved in carcinogen metabolism, increase the production of reactive oxygen species and inhibit DNA repair ${ }^{(174,177)}$. Thus, there are a variety of mechanistic pathways that may explain the relationship between alcohol and breast cancer and support epidemiological studies.

\section{Alcohol: epigenetic studies}

Epigenetic studies have revealed a trend towards decreased methylation in a cluster of cancer-related genes in primary tumours of 162 women (stage I-IV) ${ }^{(178)}$, suggesting that alcohol consumption may lead to epigenetic modifications. Another study on DNA methylation profiles in breast tumours has reported that exposure to alcohol seems associated with a specific DNA methylation pattern $^{(178)}$. Therefore, the evidence supporting an impact of alcohol on breast cancer risk seems convincing, but understanding the relationship between alcohol intake and epigenetic modifications is necessary to unravel the basis for an effect on tumour development.

\section{Fat intake: epidemiological studies}

A correlation between high-fat diets and risk of cancer has been noted for more than two decades ${ }^{(94,179-182)}$. The WCRF did not find convincing evidence for a relationship between dietary fat intake and breast cancer risk; however, the support resource shows in the meta-analysis of case-control studies ( $n$ 22) a modest significant increased risk (OR 1.03) for total fat. Also, in a combined analysis of twelve case-control studies, there was a positive association between breast cancer risk and saturated fat intake ${ }^{(183)}$. In contrast, the results of a meta-analysis of eight prospective trials did not support a strong association between breast cancer incidence and total fat ${ }^{(184)}$. Not all studies associate increased intake of total fats with increased breast cancer risk, but these studies have shown relationships with other cancer sites ${ }^{(185,186)}$.

Certainly, one of the issues that complicates any epidemiologically based study is that fat intake is comprised of a variety of fats, including animal or saturated fats, polyunsaturated fats such as $n-3$ or $n$-6 PUFA, MUFA and trans-fatty acids. Fatty acid types have differential effects on the progression of diseases and different mechanisms of action. Therefore, each of the family of fats, or individual fatty acids, may have a different impact on the development and progression of breast cancer. Unfortunately, the ability to measure the dietary levels of fatty acids accurately is very limited. It is not surprising then that studies produce opposite results. For example, the European Prospective Investigation into Cancer and Nutrition (EPIC)-Postdam study showed that a high intake of SFA, MUFA, $n-3$ PUFA 
and n-6 PUFA led to a two-fold increase in breast cancer risk when comparing highest to lowest tertiles of processed meat, animal fats and margarine ( $n 15351$ with an average follow-up of 6 years $)^{(187)}$. No association could be noted between breast cancer risk and specific fatty acids or fat intake patterns ${ }^{(87)}$. Similar conclusions were made for a meta-analysis of prospective studies on animal fat ${ }^{(188)}$. Furthermore inverse associations were found between breast cancer risk and dietary patterns relying on animal product intake as well as dietary patterns rich in unsaturated fat $^{(108)}$. Data obtained using the lipidome approach (i.e. an integrated view of the complex lipid interaction or lipid profile based on adipose tissue samples) suggested that elevated MUFA intake and a low $n-6: n-3$ fatty acids ratio intake were associated with decreased breast cancer risk ${ }^{(189)}$. In contrast, trans-fatty acids, for which the main source is industrial hydrogenation processing (for example, margarine), have been linked to an increase in breast cancer risk $^{(190)}$. Results of the Nurses' Health Study, in a 20-year follow-up, showed no association between fats and breast cancer risk, even when specific types of fat, and ER or PR status were considered ${ }^{(191)}$. However, fat intake during adolescence may have to be further investigated, as the RR for breast cancer in premenopausal women in the Nurses' Health Study was 1.35 in the highest quintile of dietary fat intake (mean $142 \mathrm{~g} / \mathrm{d}$ ) compared with the lowest quintile (mean 105 g/d) (OR 1.35; 95\% CI 1.00, 1.81) ${ }^{(192)}$. Overall, epidemiological studies reveal highly variable results, and until dietary intake of specific types of fats can be measured with greater accuracy or precise status measures are developed, these study designs are unlikely to decipher relationships between dietary fats and breast cancer.

\section{Fat intake: animal studies}

Consistent with epidemiological data in human subjects, a significant body of literature shows that diets high in fat increase the progression of mammary tumours in rodents $^{(193,194)}$. Rodent studies consistently show that a high-fat diet promotes hyperproliferation in the mammary gland, and shortened latency and increased incidence of carcinogen-induced mammary tumours ${ }^{(195,196)}$. As noted above, the interpretation of these studies is complicated by greater adiposity and excess energy intake associated with the intake of high-fat diets. When energy intake is controlled in animal studies, the effect of fat intake is weak or eliminated $^{(197,198)}$, suggesting that energy intake may be the most important factor for breast cancer risk.

\section{Fat intake: mechanisms}

Multiple mechanisms are proposed to underlie an impact of fats on breast cancer, but the specific pathways remain unclear $^{(199)}$. Enrichment of cell membranes with dietary fats may alter membrane fluidity and potentially the size and distribution of lipid rafts $^{(200)}$ and the level of oxidative stress. Specific types of fat, provided with the diet and normally stored in cell membranes, are metabolised very differently in cells, serving not only as an energy substrate that can alter membrane susceptibility to lipid oxidation, but also produce biologically active signals. For example, arachidonic acid and EPA are precursors for eicosanoids, which are potent intracellular signals. More specifically, $n$-3 fatty acids can inhibit inflammatory mediators that are proposed to promote cancer progression. Different types of lipids may differentially affect breast cancer risk, and the mechanisms involved are likely to also differ depending on the type of lipid ${ }^{(201)}$. The biological effects of $n-6$ PUFA and $n-3$ PUFA proposed to promote and suppress cancer progression, respectively, are diverse and include characteristics of cells such as proliferation and apoptosis, as well as an influence on angiogenic factors ${ }^{(202)}$ that play a critical role in cancer development and progression. Interestingly, a high dietary intake of n-6 PUFA during pregnancy increases mammary tumorigenesis in the offspring in rats ${ }^{(152)}$, suggesting a long-lasting effect of fats on cancer risk. Another link with mammary cancer susceptibility was found in a study focused on a high-fat diet in rats, a diet which has been linked with increased incidence of induced mammary tumours in the offspring ${ }^{(203)}$. Interestingly, the normal mammary tissue of offspring from mothers fed a high-fat diet during pregnancy was altered, with denser epithelial tree and higher number of proliferating cells compared with controls. The offspring of high-fat diet-fed mothers had higher birth weight and displayed shorter latency for mammary tumour development.

Thus, there is a mechanistic basis for the purported relationship between several specific fatty acids and breast cancer risk. However, deciphering the mechanisms will require well-defined models in order to later on translate these results into population studies and interventions.

\section{Fat intake: epigenetic studies}

There are virtually no studies on the interaction of fat intake and epigenetics as it relates to breast cancer. There have been some studies unrelated to the mammary gland, such as that showing a DNA hypomethylating effect of a high-fat diet globally and at the promoter of specific genes in the brain ${ }^{(204)}$. Another study suggests an impact on mammary tissue by showing that ER methylation was lost in the mammary tissue of a majority of rats at an increased risk of developing breast cancer due to manipulation of dietary fat intake in utero ${ }^{(205)}$. Unfortunately, in whole organisms it is difficult to separate the effect of a high-fat diet from obesity. Therefore, studies performed in appropriate cell model systems are necessary to tease out a possible link between specific fatty acids and epigenetic mechanisms. For instance, our recent results in cultures of non-neoplastic human mammary epithelial cells that mimic pre- and postglandular differentiation stages 
indicate that fatty acid treatment that protects the normal phenotype also globally has an impact on the level of a number of histone modifications (K McDole and S Lelièvre, unpublished results). It will be important to identify which modifications are sustained and the specific genomic regions involved.

\section{Carbohydrates, glycaemic index and glycaemic load: epidemiological studies}

Carbohydrates and carbohydrate quality could influence breast cancer risk potentially by affecting insulin resistance and plasma levels of insulin and glucose ${ }^{(10)}$. To date, twelve prospective cohort studies have shown inconsistent associations between total carbohydrate, glycaemic index, glycaemic load and breast cancer ${ }^{(206)}$. Nevertheless, data from Mexico, where carbohydrates account for close to $64 \%$ of energy intake in the population, support an association between carbohydrate intake as well as glycaemic load and breast cancer among pre- and postmenopausal women ${ }^{(207)}$. High intake of refined carbohydrates may have stronger associations with breast cancer risk in populations genetically susceptible to insulin resistance, such as in Mexico, particularly when combined with obesity and low levels of physical activity ${ }^{(208)}$. Further, a higher glycaemic index during adolescence is associated with an increased risk for breast cancer in adults in the Nurses' Health Study II $^{(209)}$. In addition, carbohydrate quality may differently affect breast tumour types including positive associations of carbohydrate intake, glycaemic index and glycaemic load with risk of $\mathrm{ER}+/ \mathrm{PR}-$ breast cancer, but not $\mathrm{ER}+/ \mathrm{PR}+$ or $\mathrm{ER}-/ \mathrm{PR}-$ breast tumour ${ }^{(210)}$, or an increased risk of ER- breast cancer ${ }^{(211,212)}$. Thus, evidence of an association between carbohydrate intake, glycaemic index and glycaemic load is conflicting and may be confounded by insulin resistance and the type of tumour.

\section{Carbohydrates, glycaemic index and glycaemic load: mechanisms}

The mechanisms underlying the relationship between carbohydrate intake, and particularly glycaemic index, and breast cancer risk is proposed to be through greater insulin action. Chronically raised insulin levels may increase carcinogenesis in breast tissue by directly stimulating insulin receptors. Insulin can also reduce plasma and tissue levels of IGF-binding proteins 1 and 2, which may in turn increase the availability of IGF- ${ }^{(68)}$, and experimental studies have revealed strong proliferative and anti-apoptotic effects of IGF-1 in breast tissue ${ }^{(213)}$. A recent pooled analysis including seventeen prospective studies reported a positive association between IGF-1 and the risk of developing ER + tumours (OR 1.38; $95 \%$ CI 1.14, 1.68; comparing highest with lowest fifth) ${ }^{(214)}$. Therefore, potential mechanisms to explain the impact of carbohydrates on breast tumour development include higher insulin levels (similar to obesity) and increased availability of IGF-1, both of which activate cellular responses consistent with cancer progression.

\section{Carbohydrates, glycaemic index and glycaemic load: epigenetics}

Similar to fatty acids, the specific effect of carbohydrates on the epigenome has not been examined. Most studies currently available are linked to obesity. As mentioned above, specific three-dimensional cell models that mimic phenotypically normal breast glandular differentiation might be an interesting first approach to sort out epigenetic effects directly related to carbohydrates.

\section{Micronutrients}

Research pertaining to elements required in minute amounts in the diet has generated many reports, particularly in regards to an effect on epigenetic mechanisms. Among the most studied elements for breast cancer are folate, vitamin D and carotenoids.

\section{Folate: epidemiological studies}

Most prospective studies do not provide evidence of an association between folate intake and breast cancer risk $^{(215-217)}$. In contrast and consistent with the literature related to colorectal cancer ${ }^{(218)}$, there is also evidence to support that folate supplementation may increase the risk for breast cancer ${ }^{(219)}$. Interestingly, a benefit from folate intake is observable in individuals with low folate status (in non-vitamin users, highest $(356 \mu \mathrm{g} / \mathrm{d}) v$. lowest $(\leq 159 \mu \mathrm{g} / \mathrm{d})$, OR $0.61 ; 95 \%$ CI $0.41,0.93)$, suggesting a protective effect against breast cancer only in nonsupplemented vitamin B users ${ }^{(220)}$. Protective effects have also been observed in populations with low folate status, in which vitamin supplementation is infrequent ${ }^{(221-225)}$. In a case-control study conducted among Mexican populations, women with the highest folate intake (mean $454 \mu \mathrm{g} / \mathrm{d})$ compared with women with the lowest intake (mean $224 \mu \mathrm{g} / \mathrm{d}$ ) had a risk for breast cancer of 0.64 $(95 \% \text { CI } 0.45,0.90)^{(220)}$. Furthermore, vitamin $\mathrm{B}_{12}$, a coenzyme in folate metabolism, might be associated with a lower risk of breast cancer and low vitamin $B_{12}$ intake may reduce the potential protection conferred by folate against breast cancer development ${ }^{(219,221,226,227)}$.

Folate studies are further complicated by the fact that, as for other dietary components, additional factors may have an impact on the relationship between folate intake and breast cancer risk. For example, an inverse association between breast cancer development and circulating folate levels among alcohol drinkers has been noted ${ }^{(216,228)}$. Ethanol may induce a physiological deficiency that affects the one-carbon metabolism involved in the epigenetic control of gene transcription by reducing folate absorption 
from the gastrointestinal tract or by inhibiting enzymic activity $^{(218)}$. The impact of folate may also be related to the tumour type, since the incidence of ErbB2-positive breast cancers is increased in women in the highest tertile of plasma folate compared with the lowest ${ }^{(229)}$.

\section{Folate: animal models}

The impact of folic acid on the initiation and progression of mammary tumorigenesis in animal models is complex and dependent on the dose and timing of dietary manipulation. Generally, studies in animal models support that folate deficiency is associated with a reduced risk of developing mammary tumours, although some studies show no effect when dietary intervention is initiated before chemical induction of tumorigenesis ${ }^{(27,230-232)}$. On the other hand, folate deficiency developed after tumour initiation is shown to inhibit the progression of mammary neoplasias $^{(233-235)}$, suggesting that high-folate diets may enhance the progression of tumours.

\section{Folate: mechanisms}

Knowing the mechanisms of folate impact on the mammary gland would help greatly in deciphering how to integrate this nutrient in prevention studies. As mentioned above, epidemiological studies suggest an interaction between alcohol intake and folate on risk of cancers, and there is a mechanistic basis for this observation, as alcohol has an impact on folate metabolism ${ }^{(236)}$. Overall, the results suggest that folate deficiency may increase initiation, but decrease progression of breast cancer, which is consistent with the concept first proposed for colon cancer that folate prevents the development of cancers, but high folate intake may promote progression of already established tumours ${ }^{(218)}$. This discrepancy might in part be explained by epigenetic effects.

\section{Folate: epigenetics}

Folate is a central player in one-carbon metabolism, including methylation of DNA. It is converted to 5,10-methylenetetrahydrofolate (MTHF), the metabolites of which are important for the synthesis of DNA components, guanine and adenine. Importantly, the product of MTHF reductase, 5-methyltetrahydrofolate, is a methyl donor for the conversion of homocysteine to methionine, which ultimately serves in the form of $S$-adenosylmethionine for a variety of reactions, including methylation of DNA. Polymorphism in MTHF reductase has been shown to interact with B vitamins to modulate breast cancer risk ${ }^{(220)}$. Indeed, there is evidence that folate deficiency may lead to global hypomethylation $^{(220)}$. Thus, there is a strong mechanistic basis for a role of alterations in dietary intake levels of folate in the initiation and progression of breast cancer by acting on DNA integrity, synthesis, repair and methylation.
So far, studies have suggested that folate may confer protection in early carcinogenesis and also promote cancer growth later during the neoplastic process, including that of mammary tumours ${ }^{(219,237)}$. This is a plausible scenario because, as the disease progresses, the organisation of the cell nucleus, including the genome, may be modified $^{(12)}$. Therefore, one-carbon metabolism-mediated DNA methylation triggered by folate might affect genes that are protecting against breast cancer development as well as genes that are promoting tumour development and progression depending whether or not nuclear organisation renders these genes accessible for epigenetic modification.

One critical way for nutrients to affect the epigenome is to influence the availability of methyl groups. By doing so they could modify the methylation status of DNA and, thus, gene transcription ${ }^{(45)}$. In the preceding paragraph, it was explained that folate contributes to the one-carbon metabolism pathway ${ }^{(238)}$. Particularly, folate carries a methyl group used for the synthesis of the methyl donor metabolite $S$-adenosylmethionine ${ }^{(239)}$, and could also make an impact on the activity of methyltransferase via $S$-adenosylhomocysteine ${ }^{(45)}$. As a result, bioactive foods can modify the epigenetic landscape, possibly leading to permanent gene silencing.

The epigenetic effect might also be critical for the influence of maternal diet on the offspring. Folate supplementation before and during pregnancy in rats increased the risk of tumour development induced chemically by 7,12-dimethylbenz(a)anthracene (DMBA) in the offspring compared with a control (adequate) diet, and induced a decrease in global DNA methylation ${ }^{(240)}$. Folate supplementation during pregnancy and weaning reduced the number of mammary terminal end buds, a marker of breast cancer risk, suggesting a protection from breast cancer compared with a control diet ${ }^{(241)}$. The potential link between terminal end bud density and an effect on DNA methylation by folate remains to be clarified. In humans, it is also possible to influence methylation in the offspring via nutritional changes in the mother. For instance, studies have shown that folic acid supplementation of women during the periconceptional time increases $I G F-2$ gene methylation in children ${ }^{(242)}$.

The broad mechanisms by which foods seem to influence the epigenome (for example, via one-carbon metabolism and methyltransferase activity) could potentially affect many genes. Indeed, a minimum of $60 \%$ of genes are proposed to be methylated. Also a majority of genes will be sensitive to acetylation and methylation of histones. Yet, as shown with the example of folate, only certain genes seem to be responsive to the modulation of common epigenetic pathways. A plausible hypothesis is that only genes in a receptive chromatin environment will respond to such broad epigenetic modulation. Therefore, probably the effect of dietary compounds will depend on the gene, the cell type (with its specific nuclear 
organisation) ${ }^{(243)}$, the cell status (i.e. proliferation) and previous epigenetic conditions. For instance, deprivation of folate has been associated with gene hypermethylation specifically in the liver in a rat model ${ }^{(230,244)}$. Timing might also be important, as the effect of folate might be opposite depending on when it is given. For instance, it stimulates tumour development if a preneoplastic lesion is already in place $^{(245)}$. Therefore, promoting or preventing methylation and acetylation reactions via foods could have various outcomes depending on when during life such an influence occurs. Of particular interest is the consequence of diet received before mammary gland development on epigenetic modifications and breast cancer risk.

Overall, there is evidence of a biphasic effect of folate deficiency and supplementation on breast cancer risk depending on the timing of dietary intervention and involving epigenetics, but the results remain controversial and the underlying mechanisms are not definitively determined.

\section{Vitamin D}

Vitamin D is one of the most studied micronutrients as a cancer-preventive agent, but the controversy regarding its potential use in prevention is not yet settled. A main reason is that, like for folate, the efficacy of vitamin D may depend on individual baseline level, dose and supplementation period.

\section{Vitamin D: epidemiological studies}

Results from many epidemiological studies support that vitamin $\mathrm{D}$ is associated with reduced breast cancer risk $^{(246,247)}$. First were ecological studies showing a relationship between exposure to UV light and reduced risk of breast cancer ${ }^{(248)}$. The potential explanation for this relationship is that vitamin $\mathrm{D}$ is synthesised in the skin under the influence of UV light. Both UV light-produced vitamin $\mathrm{D}$ and dietary vitamin $\mathrm{D}$ are then converted in the liver to 25-hydroxyvitamin D (25OHD), the serum levels of which are used as a vitamin D status marker. In a pooled analysis, the results revealed that $25 \mathrm{OHD}$ serum levels of approximately $52 \mathrm{ng} / \mathrm{ml}$ were associated with a $50 \%$ reduction in breast cancer risk compared with women with $25 \mathrm{OHD}$ levels $<13 \mathrm{ng} / \mathrm{ml}^{(246)}$. One casecontrol study revealed that women with $25 \mathrm{OHD}$ plasma concentration $<50 \mathrm{nmol} / 1$ had five times greater risk of developing breast cancer than women with concentrations exceeding $150 \mathrm{nmol} / \mathrm{l}^{(249)}$. Similarly, a meta-analysis reported a $45 \%$ decrease in breast cancer risk among women in the highest quartile $(60 \mathrm{nmol} / \mathrm{l})$ of circulating $25 \mathrm{OHD}$ compared with women with the lowest level ${ }^{(250)}$. Epidemiological studies have also shown an inverse association between vitamin $\mathrm{D}$ intake or serum 25OHD and breast cancer development, in both premenopausal women $^{(251,252)}$ and postmenopausal women ${ }^{(253)}$.
Similar to other dietary components, menopausal status may play a role in the association between vitamin $\mathrm{D}$ and breast cancer risk. In an ecological study, the inverse relationship between geographical UV exposure and breast cancer was specific to premenopausal women ${ }^{(254)}$. Similarly, in the Nurses' Health Study ( $n$ about 90000) with an approximate 14-year follow-up, vitamin D intake was inversely associated with breast cancer risk only in premenopausal women, which is consistent with results from the Cancer Prevention Study II Nutrition Cohort. In the latter, dietary vitamin D intake was not associated with breast cancer risk in postmenopausal women ${ }^{(25)}$. Thus, although a strong body of work supports the relationship between vitamin $\mathrm{D}$ and breast cancer, the results of epidemiological studies remain controversial, and discrepancies noted in the relationship may be due to the influence of other factors. It is hoped that ongoing trials will take note of the many variables that could affect the outcome of the results to better pinpoint the relationship between vitamin $\mathrm{D}$ and breast cancer.

\section{Vitamin D: animal studies and mechanisms}

Vitamin D is best characterised for its role on the regulation of Ca status. High vitamin D status leads to the suppression of serum parathyroid hormone levels. Parathyroid hormone is a strong stimulator of renal 25-hydroxyvitamin $\mathrm{D}-1 \alpha$ hydroxylase which catalyses the conversion of $25 \mathrm{OHD}$ to 1,25 -dihydroxyvitamin $\mathrm{D}\left(1,25(\mathrm{OH})_{2} \mathrm{D}\right)^{(256,257)}$, leading to an inverse relationship between vitamin $\mathrm{D}$ status (serum 25OHD levels) and serum $1,25(\mathrm{OH})_{2} \mathrm{D}$. This inverse relationship is difficult to reconcile with observations that higher vitamin $\mathrm{D}$ status is associated with a decrease in breast cancer risk but $1,25(\mathrm{OH})_{2} \mathrm{D}$ directly inhibits cancer-relevant endpoints in cells. However, extrarenal $1 \alpha$-hydroxylase enzymes have also been identified in a variety of tissues ${ }^{(258)}$ and in mammary epithelial cells ${ }^{(259)}$, which may lead to greater local production of $1,25(\mathrm{OH})_{2} \mathrm{D}$ under conditions of high vitamin D status ${ }^{(260)}$.

The activity of $1,25(\mathrm{OH})_{2} \mathrm{D}$ is regulated through vitamin $\mathrm{D}$ receptor (VDR)-mediated transcriptional regulation as well as rapid, non-genomic actions. The VDR, a member of the steroid hormone receptor family, mediates $1,25(\mathrm{OH})_{2} \mathrm{D}$ transcriptional actions by heterodimerising with retinoid $\mathrm{X}$ receptor and interacting with vitamin $\mathrm{D}$ response elements to up-regulate and down-regulate a wide variety of genes ${ }^{(261,262)}$. Other evidence supports that $1,25(\mathrm{OH})_{2} \mathrm{D}$ regulates kinase signalling cascades involving protein kinase $\mathrm{C}$, extracellular signal-regulated protein kinases 1 and 2, phosphoinositide-3-kinase, and $\mathrm{Src}^{(263-266)}$, which are generally shown to be rapid and independent of new RNA and protein synthesis ${ }^{(263,267)}$.

Consistent with the epidemiological results, there is also substantial evidence in animal models to support a protective effect of vitamin D for breast cancer ${ }^{(268)}$. For example, susceptibility to hyperplasia and tumours in the 
mammary gland is greatly increased in mice lacking the $\mathrm{VDR}^{(269,270)}$. Further, mammary gland proliferation and tumour development is reduced by high vitamin $\mathrm{D}$ intake in animals ${ }^{(271,272)}$.

Overall, in vitro studies have shown that vitamin D can regulate critical characteristics of cells necessary for carcinogenesis, including inhibiting cell proliferation, promoting apoptosis and reducing angiogenesis ${ }^{(273)}$. Furthermore, alterations in genes related to vitamin D metabolism have been associated with breast cancer risk ${ }^{(268)}$. Thus, there is substantial evidence in both animal and cell culture studies to support that vitamin D reduces breast cancer risk. However, as for fatty acids, the translation of the information to human populations will require consideration of many factors and well-designed clinical trials.

\section{Vitamin D: intervention studies}

The largest clinical trial in which the impact of dietary vitamin D on breast cancer development was investigated is the Women's Health Initiative. In this study, no impact of vitamin D supplementation on breast cancer risk was noted $^{(274)}$. However, the levels of vitamin D supplement used in this trial $(400 \mathrm{IU} / \mathrm{d} ; 10 \mu \mathrm{g} / \mathrm{d})$ are now considered potentially too low to elicit maximal effects on bone and, thus, also the proposed effect on breast cancer development. In addition, because the duration was only 7 years, this trial does not represent the testing of a meaningful intervention to prevent breast cancer. An example of the issue of timing of the intervention is shown in the study by Lappe et al. who completed a randomised placebocontrolled Ca and vitamin D intervention trial in postmenopausal women ( $>55$ years; $n$ 1179), followed during 4 years ${ }^{(275)}$. The RR of developing breast cancer with $\mathrm{Ca}$ supplementation (about $1450 \mathrm{mg} / \mathrm{d}$ ) alone was 0.54 , and no difference was found for the group with both $\mathrm{Ca}$ and vitamin D (1100 IU/d $(27.5 \mu \mathrm{g} / \mathrm{d})$, RR 0.40). It was hypothesised that vitamin $\mathrm{D}$ might be less effective in preventing breast cancer development if the cancer is already present, although not yet detectable with current screening methods. Therefore, women who were diagnosed with breast cancer in the first year of the trial were excluded from the analysis. In that case the risk of developing breast cancer in the vitamin D plus Ca group was significantly reduced (RR 0.23) compared with the placebo and compared with Ca supplementation alone (RR 0.59). This study provides strong evidence that vitamin $\mathrm{D}$, at least in the presence of $\mathrm{Ca}$, significantly reduces breast cancer risk and reveals that the timing of the intervention (i.e. before breast cancer is present) may be critical.

\section{Vitamin D: epigenetics}

First, epigenetic modifications are suggested to alter the effects of $1,25(\mathrm{OH})_{2} \mathrm{D}$. For example, the use of inhibitors to epigenetic modifications restores signals associated with anti-proliferative effects in vitamin D-resistant breast cancer cells ${ }^{(276)}$. Suppression of $1 \alpha$-hydroxylase expression, which influences the production of the most active form of the vitamin, is modified in part by histone deacetylation and mediation of this repression by the VDR requires DNA methylation in the promoter of the gene $^{(277)}$. Further, epigenetic alterations in the gene producing the 24-hydroxylase that mediates the first step in the degradation of $1,25(\mathrm{OH})_{2} \mathrm{D}$ was shown in full-term human placental tissue, but not methylation of the VDR and $1 \alpha$-hydroxylase genes ${ }^{(278)}$. Reduction in 24-hydroxylase expression is mediated at least in part by methylation of the promoter in human prostate cancer ${ }^{(279,280)}$. Therefore, epigenetic modifications may alter the metabolism as well as the action of vitamin D, but little information is available in breast tissue. On the other hand, although the active metabolite, $1,25(\mathrm{OH})_{2} \mathrm{D}$, was shown to have an effect on gene expression in breast cancer cells ${ }^{(281)}$, the role of vitamin $\mathrm{D}$ in modifying the epigenome in relation to breast cancer has not been explored. Nevertheless, nuclear receptors (to which the VDR belongs) and associated mediators are known to influence chromatin remodelling and epigenetic modifications. In conclusion, there is an interaction of vitamin $\mathrm{D}$ with the epigenome, but a consequence for breast cancer risk is not clear.

\section{Carotenoids: epidemiological studies}

A substantial literature exists investigating the relationship between carotenoids and cancer ${ }^{(46,282,283)}$. In epidemiological studies, intake of carotenoids is assessed both by dietary analysis and serum levels of the carotenoids. Some studies have indicated a protective effect of carotenoids $^{(284,285)}$, whereas other studies showed no association with breast cancer ${ }^{(286-289)}$. The putative effect of carotenoids may be modified by age or menopausal status since an inverse association with breast cancer risk was noted in premenopausal women rather than in postmenopausal women $^{(290)}$. Furthermore, the potential impact of carotenoids may be greater when associated with other lifestyle factors. This is exemplified by the link between carotenoids and the reduced risk of invasive breast cancer in premenopausal, but not postmenopausal, smokers ${ }^{(290)}$.

It is important to note that carotenoids are a family of compounds including retinol, retinyl palmitate, $\alpha$-carotene, $\beta$-carotene, $\beta$-cryptoxanthin, lutein and lycopene. Like fats, the type of carotenoid may have a different impact on the risk of breast cancer. A nested case-control study for women who donated blood before diagnosis revealed that women who developed breast cancer had significantly lower serum concentrations of $\beta$-carotene, lycopene and total carotene than the breast cancer-free controls ${ }^{(291)}$. Similarly, serum lycopene levels have been associated with a reduced breast cancer risk ${ }^{(286)}$. Contradictory results exist among the types of carotenoids as revealed by the Women's Health Initiative since baseline serum levels of 
$\alpha$-carotene and $\beta$-carotene were negatively associated, while lycopene levels were positively associated with invasive breast cancer in postmenopausal women ${ }^{(292)}$. Therefore, the relative levels of the different types of carotenoids are important to take into account as well as a potential influence from other lifestyle factors.

\section{Carotenoids: mechanisms}

A number of mechanisms have been examined that may underlie the purported relationship between carotenoids and breast cancer development. Cell culture studies show that retinoids may reduce proliferation and induce differentiation of epithelial cells ${ }^{(293,294)}$. Carotenoids function as antioxidants and, thus, may also protect DNA from damage induced by reactive oxygen species. On the other hand, at high doses, $\beta$-carotene may act as a pro-oxidant, hence potentially promoting tumorigenesis ${ }^{(295,296)}$. Therefore, although mechanisms exist to explain the relationship between carotenoids and breast cancer, there is still much to learn about the effect of these nutrients on the breast tissue.

\section{Carotenoids: epigenetic studies}

Lycopene has been reported to influence the epigenome by partially demethylating the tumour suppressor gene GSTP1 (glutathione S-transferase P1) in breast cancer cells. Interestingly, treatment of non-neoplastic breast epithelial cells MCF10A with lycopene led to demethylation of $R A R \beta 2$ (retinoic acid receptor $\beta 2)^{(297)}$, a gene silenced before the onset of tumour development ${ }^{(298)}$. Although lycopene is currently classified as displaying a possible preventive action against cancer because of its influence on the epigenome, additional mechanistic studies are needed to clearly establish this possibility and will require the use of appropriate cell models.

\section{The complexity of epigenetics and diet interaction}

Most of the studies related to the epigenome, diet and cancer have focused on DNA methylation. Yet, as explained in the introduction, a large area of epigenetics relies on the study of histone modifications. Unfortunately, much less is known regarding the potential effect of foods and nutrients on histones. One of the rare studies suggests that resveratrol contained in red wine and possibly associated with protection against cancer development $^{(299)}$ could lead to histone deacetylase (HDAC) inhibition via an effect on Sirt $1^{(300,301)}$, thus potentially promoting histone hyperacetylation and preventing transcriptional repression.

The influence of diet early in life on cancer development occurring years later has to be regarded as a life-course perspective on cancer risk' to quote Burdge et al. ${ }^{(37)}$. Indeed, it has been proposed that breast cancer might develop over 10 to 30 years; therefore it seems logical that some of the initiating events would occur early in life, even as soon as embryonic development, either because of epigenetic imprinting from the parent gametes or because of nutrition received in utero (or before puberty). Further emphasis on studies related to the impact of diet early in life on breast cancer development is critical. But the truth remains that not all women subjected to risk factors early in life will develop breast cancer. It is likely that the complex epigenetic profile of each individual will provide a different soil in each individual and, thus, a different response to risk factors. Yet, it is likely that variations in soils are not infinite; rather, a subset of specific genes might have to be altered to favour breast cancer development. By finding or defining the protective signature of the epigenome in the breast (i.e. an epigenetic profile that prevents tumour development), we might be able to develop ways to return to this signature once it is altered and use this signature as a method to assess preventive strategies. Indeed, it is critical to develop biomarkers of breast cancer initiation to complete cost-effective and rapid assessment of the impact of potential preventive agents on the development of the disease. It seems that understanding the link between diet, the epigenome and specific types of breast cancers might be a way to achieve this goal.

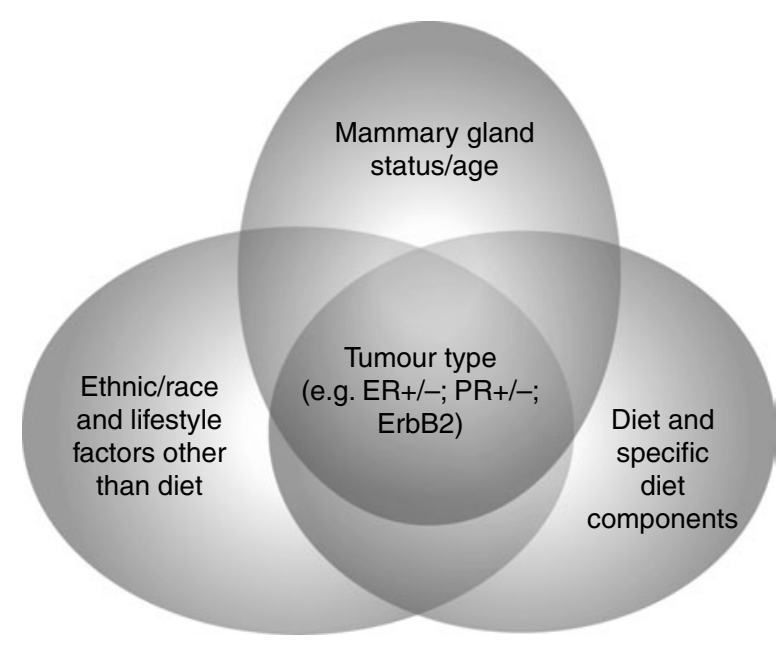

Fig. 3. Venn diagram of a relationship between diets/food components and factors that influence their impact on breast cancer risk. Major life characteristics share specific relationships with diets/food components when it comes to breast cancer. These characteristics include the stage of mammary gland development (which encompasses menopausal status/age) and the individual's background (race/ethnicity and lifestyle other than dietary habits). The combination of these different factors might explain why certain nutrients will have an impact on the development of a certain type of breast tumour. Such knowledge is critical for optimal primary prevention, as it suggests that (1) the study of the impact of diets/food components on breast cancer has to take into account diversity and (2) the link between the development of a certain type of breast tumour and nutrition has to be further scrutinised, notably via the identification of the early alterations in the breast specific to a given type of neoplasia. ER +, oestrogen-positive; ER-, oestrogen-negative; $\mathrm{PR}+$, progesterone-positive; $\mathrm{PR}-$, progesterone-negative. 


\section{Conclusion}

It is evident from the studies reported in the present review that there is a divergence in the results from population studies compared with more controlled conditions. There are several reasons for this lack of consensus beside the possibility of confounding factors and the many differences in the experimental design and endpoints. We need to resolve the discrepancies to launch a global effort to fight the rise of breast cancer incidence which includes diverse populations. Indeed, few studies are available from LMI countries where variability in food intake is large and nutritional supplementation less prevalent. In addition, stratification of breast cancer by specific characteristic has to be further considered, particularly breast cancer grades, receptor status (ER, PR, HER2 (human epidermal growth factor receptor-2)) and other molecular classification, as specific diets and nutrients interact with these factors to promote or protect from a defined type of breast cancer (Fig. 3). Finally, it seems that dietary factors are particularly important in determining premenopausal breast cancer risk. Efforts ought to be placed on developing studies in countries where breast cancer incidence is high in younger women.

Gene-diet interaction and long-term epigenetic mechanisms are paramount in determining breast cancer risk. Further investigations are needed in order to unravel the role of diet on long-term and temporary epigenetic modifications. On a side note, another aspect that should not be forgotten in future studies is the possibility for foods to convey environmental pollutants, some of which have hormonal activity, and which could also contribute to epigenetic changes. The endeavour of identifying the meaning of epigenetic alterations will require taking into account the complexity of histone changes. Indeed, one nutrient might have different effects depending on the chromatin environment of a specific gene. Therefore, global epigenetic modifications need to be correlated with modifications at specific gene loci and new technologies, notably microscopy-based imaging ${ }^{(302)}$, might enable scientists to perform these studies with highthroughput efficacy. There is increasing evidence that large-scale chromatin organisation or higher-order chromatin organisation that involves gene neighbourhoods or groups directs tissue development and differentiation $^{(303,304)}$. Therefore, as the epigenome is modified by environmental stimuli, many genes might change expression although only a few genes will be required to determine breast cancer development. These few genes need to be identified and their epigenetic environment scrutinised. Similarly, understanding the impact of diet on methylases and demethylases specific to certain histone modifications and on chromatin remodelling complexes involved in facilitating or preventing gene transcription would help unravel mechanisms involved in epigenetic alterations that lead to breast cancer. Animal and appropriate cell culture models should help sort through key genes for breast cancer initiation and their epigenetic susceptibility to diet. Animal models to study mammary cancer prevention are well defined but they do not always represent the behaviour of human cells. Implementing the use of powerful human cell models of phenotypically normal mammary differentiation and early stages of tumour development provided by threedimensional cell culture ${ }^{(305)}$, instead of using cancer cells or cells in flat monolayer culture that lack tissue morphogenesis, should bring significant information regarding the molecular mechanisms involved in the impact of food on the breast epithelium.

\section{Acknowledgements}

The present review was supported by The National Institutes of Health (R25CA128770 to D. T. and S. A. L., and R01CA112017 to S. A. L.) and the Komen Foundation for the Cure (BCTR-0707641 to S. A. L.). All three co-authors contributed to ideas and writing for this paper. The present review is part of the International Breast Cancer and Nutrition (IBCN) Project initiated at Purdue University.

The authors declare no conflict of interest.

\section{References}

1. Ferlay J, Shin H-R, Bray F, et al. (2010) Estimates of worldwide burden of cancer in 2008: GLOBOCAN 2008. Int J Cancer 127, 2893-2917.

2. Franco-Marina F, Lazcano-Ponce E \& Lopez-Carrillo L (2009) Breast cancer mortality in Mexico: an age-periodcohort analysis. Salud Publica Mex 51, Suppl. 2, s157-s164.

3. Velasquez-De Charry LC, Carrasquilla G \& Roca-Garavito S (2009) Equity in access to treatment for breast cancer in Colombia (article in Spanish). Salud Publica Mex 51, Suppl. 2, s246-s253.

4. Lozano-Ascencio R, Gomez-Dantes H, Lewis S, et al. (2009) Breast cancer trends in Latin America and the Caribbean (article in Spanish). Salud Publica Mex 51, Suppl. 2, s147-s156.

5. Porter P (2008) "Westernizing" women's risks? Breast cancer in lower-income countries. N Engl J Med 358, 213-216.

6. Dunn BK, Agurs-Collins T, Browne D, et al. (2010) Health disparities in breast cancer: biology meets socioeconomic status. Breast Cancer Res Treat 121, 281-292.

7. Prentice RL (2008) Women's health initiative studies of postmenopausal breast cancer. Adv Exp Med Biol 617, 151-160.

8. Zeisel SH (2007) Nutrigenomics and metabolomics will change clinical nutrition and public health practice: insights from studies on dietary requirements for choline. Am J Clin Nutr 86, 542-548.

9. International Agency for Research on Cancer and World Health Organization (2008) In World Cancer Report 2008, [P Boyle and B Levin, editors]. Lyon: IARC.

10. Michels KB, Mohllajee AP, Roset-Bahmanyar E, et al. (2007) Diet and breast cancer: a review of the prospective observational studies. Cancer 109, 2712-2749.

11. Weigelt B, Baehner FL \& Reis-Filho JS (2010) The contribution of gene expression profiling to breast cancer 
classification, prognostication and prediction: a retrospective of the last decade. J Pathol 220, 263-280.

12. Lelievre SA (2010) Tissue polarity-dependent control of mammary epithelial homeostasis and cancer development: an epigenetic perspective. J Mammary Gland Biol Neoplasia 15, 49-63.

13. Plachot C \& Lelievre SA (2004) DNA methylation control of tissue polarity and cellular differentiation in the mammary epithelium. Exp Cell Res 298, 122-132.

14. Takai D \& Jones PA (2002) Comprehensive analysis of CpG islands in human chromosomes 21 and 22. Proc Natl Acad Sci U S A 99, 3740-3745.

15. Abad PC, Yagci B \& Lelièvre SA (2011) Nanocellular processes. In Encyclopedia of Nanoscience and Nanotechnology, vols 11-20 [HS Nalwa, editor]. Valencia, CA: American Scientific Publishers.

16. Hublitz P, Albert M \& Peters AH (2009) Mechanisms of transcriptional repression by histone lysine methylation. Int J Dev Biol 53, 335-354.

17. Mohammad HP, Cai Y, McGarvey KM, et al. (2009) Polycomb CBX7 promotes initiation of heritable repression of genes frequently silenced with cancer-specific DNA hypermethylation. Cancer Res 69, 6322-6330.

18. Mathews LA, Crea F \& Farrar WL (2009) Epigenetic gene regulation in stem cells and correlation to cancer. Differentiation 78, 1-17.

19. Hatziapostolou M \& Iliopoulos D (2011) Epigenetic aberrations during oncogenesis. Cell Mol Life Sci 68, $1681-1702$.

20. Law JA \& Jacobsen SE (2010) Establishing, maintaining and modifying DNA methylation patterns in plants and animals. Nat Rev Genet 11, 204-220.

21. Justin N, De Marco V, Aasland R, et al. (2010) Reading, writing and editing methylated lysines on histone tails: new insights from recent structural studies. Curr Opin Struct Biol 20, 730-738.

22. Sharma S, Kelly TK \& Jones PA (2010) Epigenetics in cancer. Carcinogenesis 31, 27-36.

23. Mani S \& Herceg Z (2010) DNA demethylating agents and epigenetic therapy of cancer. Adv Genet $\mathbf{7 0}$, $327-340$

24. Struewing JP, Hartge P, Wacholder S, et al. (1997) The risk of cancer associated with specific mutations of BRCA1 and BRCA2 among Ashkenazi Jews. $N$ Engl J Med 336, $1401-1408$

25. Ford D, Easton DF, Stratton M, et al. (1998) Genetic heterogeneity and penetrance analysis of the BRCA1 and BRCA2 genes in breast cancer families. The Breast Cancer Linkage Consortium. Am J Hum Genet 62, 676-689.

26. Suijkerbuijk KP, Fackler MJ, Sukumar S, et al. (2008) Methylation is less abundant in BRCA1-associated compared with sporadic breast cancer. Ann Oncol 19, 1870-1874.

27. Ai L, Tao Q, Zhong S, et al. (2006) Inactivation of Wnt inhibitory factor-1 (WIF1) expression by epigenetic silencing is a common event in breast cancer. Carcinogenesis 27, 1341-1348.

28. Veeck J, Bektas N, Hartmann A, et al. (2008) Wnt signalling in human breast cancer: expression of the putative Wnt inhibitor Dickkopf-3 (DKK3) is frequently suppressed by promoter hypermethylation in mammary tumours. Breast Cancer Res 10, R82.

29. Klarmann GJ, Decker A \& Farrar WL (2008) Epigenetic gene silencing in the Wnt pathway in breast cancer. Epigenetics 3, 59-63.

30. Polyak K \& Kalluri R (2010) The role of the microenvironment in mammary gland development and cancer. Cold Spring Harb Perspect Biol 2, a003244.
31. Lin HJ, Zuo T, Chao JR, et al. (2009) Seed in soil, with an epigenetic view. Biochim Biophys Acta 1790, 920-924.

32. Conway KE, McConnell BB, Bowring CE, et al. (2000) TMS1, a novel proapoptotic caspase recruitment domain protein, is a target of methylation-induced gene silencing in human breast cancers. Cancer Res 60, 6236-6242.

33. Parsons MJ, Patel P, Brat DJ, et al. (2009) Silencing of TMS1/ASC promotes resistance to anoikis in breast epithelial cells. Cancer Res 69, 1706-1711.

34. Bray GA (2002) The underlying basis for obesity: relationship to cancer. J Nutr 132, 3451S-3455S.

35. Lehmann U, Hasemeier B, Christgen M, et al. (2008) Epigenetic inactivation of microRNA gene hsa-mir-9-1 in human breast cancer. J Pathol 214, 17-24.

36. Chen J \& Xu X (2010) Diet, epigenetic, and cancer prevention. Adv Genet 71, 237-255.

37. Burdge GC, Slater-Jefferies J, Torrens C, et al. (2007) Dietary protein restriction of pregnant rats in the $\mathrm{F}_{0}$ generation induces altered methylation of hepatic gene promoters in the adult male offspring in the $\mathrm{F}_{1}$ and $\mathrm{F}_{2}$ generations. $\mathrm{BrJ}$ Nutr 97, 435-439.

38. Kovacheva VP, Davison JM, Mellott TJ, et al. (2009) Raising gestational choline intake alters gene expression in DMBAevoked mammary tumors and prolongs survival. FASEB J 23, 1054-1063

39. Collins JA, Blake JM \& Crosignani PG (2005) Breast cancer risk with postmenopausal hormonal treatment. Hum Reprod Update 11, 545-560.

40. Howell A \& Evans GD (2011) Hormone replacement therapy and breast cancer. Recent Results Cancer Res $\mathbf{1 8 8}$, 115-124.

41. Holmquist GP \& Ashley T (2006) Chromosome organization and chromatin modification: influence on genome function and evolution. Cytogenet Genome Res 114, 96-125.

42. Warri A, Saarinen NM, Makela S, et al. (2008) The role of early life genistein exposures in modifying breast cancer risk. Br J Cancer 98, 1485-1493.

43. Kim SW \& Wu G (2009) Regulatory role for amino acids in mammary gland growth and milk synthesis. Amino Acids 37, 89-95.

44. Maclennan M \& Ma DW (2010) Role of dietary fatty acids in mammary gland development and breast cancer. Breast Cancer Res 12, 211.

45. Choi SW \& Friso S (2011) Epigenetics: a new bridge between nutrition and health. Adv Nutr 1, 8-16.

46. World Cancer Research Fund and American Institute for Cancer Research (2007) Food, Nutrition, Physical Activity, and the Prevention of Cancer: A Global Perspective, pp. 289-298. Washington, DC: American Institute for Cancer Research.

47. Newmark HL (1994) Vitamin D adequacy: a possible relationship to breast cancer. Adv Exp Med Biol 364, 109-114.

48. Colditz GA \& Frazier AL (1995) Models of breast cancer show that risk is set by events of early life: prevention efforts must shift focus. Cancer Epidemiol Biomarkers Prev 4, 567-571.

49. de Assis S, Wang M, Goel S, et al. (2006) Excessive weight gain during pregnancy increases carcinogen-induced mammary tumorigenesis in Sprague-Dawley and lean and obese Zucker rats. J Nutr 136, 998-1004.

50. de Assis S, Cruz I, Warri A, et al. (2010) Exposure of rat dams to a high-fat or estradiol-supplemented diet during pregnancy alters mammary gland morphology and increases mammary cancer risk in their daughters and granddaughters. American Association of Cancer Research 101st Annual Meeting, 2931, abstract no. 2931. 
51. Tuma RS (2002) Retinoids and lung cancer: targeting the right population. J Natl Cancer Inst 94, 969-970.

52. Adissu HA, Asem EK \& Lelievre SA (2007) Threedimensional cell culture to model epithelia in the female reproductive system. Reprod Sci 14, 11-19.

53. Harvie M, Hooper L \& Howell AH (2003) Central obesity and breast cancer risk: a systematic review. Obes Rev $\mathbf{4}$, 157-173.

54. Berstad P, Coates RJ, Bernstein L, et al. (2010) A casecontrol study of body mass index and breast cancer risk in white and African-American women. Cancer Epidemiol Biomarkers Prev 19, 1532-1544.

55. Harris HR, Willett WC, Terry KL, et al. (2010) Body fat distribution and risk of premenopausal breast cancer in the Nurses' Health Study II. I Natl Cancer Inst 103, $273-278$.

56. Trentham-Dietz A, Newcomb PA, Egan KM, et al. (2000) Weight change and risk of postmenopausal breast cancer (United States). Cancer Causes Control 11, $533-542$.

57. Harvie M, Howell A, Vierkant RA, et al. (2005) Association of gain and loss of weight before and after menopause with risk of postmenopausal breast cancer in the Iowa Women's Health Study. Cancer Epidemiol Biomarkers Prev 14, 656-661.

58. Eliassen AH, Colditz GA, Rosner B, et al. (2006) Adult weight change and risk of postmenopausal breast cancer. JAMA 296, 193-201.

59. Gluckman PD \& Hanson MA (2008) Developmental and epigenetic pathways to obesity: an evolutionary-developmental perspective. Int J Obes (Lond) 32, Suppl. 7, S62-S71.

60. Catalano PM, Farrell K, Thomas A, et al. (2009) Perinatal risk factors for childhood obesity and metabolic dysregulation. Am J Clin Nutr 90, 1303-1313.

61. Danielzik S, Langnase K, Mast M, et al. (2002) Impact of parental BMI on the manifestation of overweight 5-7 year old children. Eur J Nutr 41, 132-138.

62. Silva IS, De Stavola B \& McCormack V (2008) Birth size and breast cancer risk: re-analysis of individual participant data from 32 studies. PLoS Med 5, e193.

63. Allison DB, Paultre F, Heymsfield SB, et al. (1995) Is the intra-uterine period really a critical period for the development of adiposity? Int J Obes Relat Metab Disord 19, $397-402$.

64. Loos RJ, Beunen G, Fagard R, et al. (2001) Birth weight and body composition in young adult men - a prospective twin study. Int J Obes Relat Metab Disord 25, $1537-1545$.

65. Loos RJ, Beunen G, Fagard R, et al. (2002) Birth weight and body composition in young women: a prospective twin study. Am J Clin Nutr 75, 676-682.

66. Dirx MJ, Zeegers MP, Dagnelie PC, et al. (2003) Energy restriction and the risk of spontaneous mammary tumors in mice: a meta-analysis. Int J Cancer 106, 766-770.

67. Lorincz AM \& Sukumar S (2006) Molecular links between obesity and breast cancer. Endocr Relat Cancer 13, 279-292.

68. Calle EE \& Kaaks R (2004) Overweight, obesity and cancer: epidemiological evidence and proposed mechanisms. Nat Rev Cancer 4, 579-591.

69. Barb D, Williams CJ, Neuwirth AK, et al. (2007) Adiponectin in relation to malignancies: a review of existing basic research and clinical evidence. Am J Clin Nutr 86, s858-s866.

70. Schaffler A, Scholmerich J \& Buechler C (2007) Mechanisms of disease: adipokines and breast cancer - endocrine and paracrine mechanisms that connect adiposity and breast cancer. Nat Clin Pract Endocrinol Metab 3, 345-354.

71. Mantzoros C, Petridou E, Dessypris N, et al. (2004) Adiponectin and breast cancer risk. J Clin Endocrinol Metab 89, 1102-1107.

72. Ouchi N, Parker JL, Lugus JJ, et al. (2011) Adipokines in inflammation and metabolic disease. Nat Rev Immunol 11, 85-97.

73. Ouchi N \& Walsh K (2007) Adiponectin as an anti-inflammatory factor. Clin Chim Acta 380, 24-30.

74. Miyoshi Y, Funahashi T, Kihara S, et al. (2003) Association of serum adiponectin levels with breast cancer risk. Clin Cancer Res 9, 5699-5704.

75. Cleary MP, Ray A, Rogozina OP, et al. (2009) Targeting the adiponectin:leptin ratio for postmenopausal breast cancer prevention. Front Biosci (Schol Ed) 1, 329-357.

76. Grossmann ME, Ray A, Dogan S, et al. (2008) Balance of adiponectin and leptin modulates breast cancer cell growth. Cell Res 18, 1154-1156.

77. Grossmann ME, Nkhata KJ, Mizuno NK, et al. (2008) Effects of adiponectin on breast cancer cell growth and signaling. Br J Cancer 98, 370-379.

78. Vona-Davis L \& Rose DP (2007) Adipokines as endocrine, paracrine, and autocrine factors in breast cancer risk and progression. Endocr Relat Cancer 14, 189-206.

79. Kabat GC, Kim M, Caan BJ, et al. (2009) Repeated measures of serum glucose and insulin in relation to postmenopausal breast cancer. Int J Cancer 125, 2704-2710.

80. Novosyadlyy R, Lann DE, Vijayakumar A, et al. (2010) Insulin-mediated acceleration of breast cancer development and progression in a nonobese model of type 2 diabetes. Cancer Res 70, 741-751.

81. Rabe K, Lehrke M, Parhofer KG, et al. (2008) Adipokines and insulin resistance. Mol Med 14, 741-751.

82. Subbaramaiah K, Howe LR, Bhardwaj P, et al. (2011) Obesity is associated with inflammation and elevated aromatase expression in the mouse mammary gland. Cancer Prev Res (Phila) 4, 329-346.

83. Heerwagen MJ, Miller MR, Barbour LA, et al. (2010) Maternal obesity and fetal metabolic programming: a fertile epigenetic soil. Am J Physiol Regul Integr Comp Physiol 299, R711-R722.

84. Lo CY, Hsieh PH, Chen HF, et al. (2009) A maternal high-fat diet during pregnancy in rats results in a greater risk of carcinogen-induced mammary tumors in the female offspring than exposure to a high-fat diet in postnatal life. Int $J$ Cancer 125, 767-773.

85. Zhang J, Zhang F, Didelot X, et al. (2009) Maternal high fat diet during pregnancy and lactation alters hepatic expression of insulin like growth factor- 2 and key microRNAs in the adult offspring. BMC Genomics 10, 478.

86. Vickers MH, Breier BH, Cutfield WS, et al. (2000) Fetal origins of hyperphagia, obesity, and hypertension and postnatal amplification by hypercaloric nutrition. Am J Physiol Endocrinol Metab 279, E83-E87.

87. Velie EM, Schairer C, Flood A, et al. (2005) Empirically derived dietary patterns and risk of postmenopausal breast cancer in a large prospective cohort study. $\mathrm{Am} \mathrm{J}$ Clin Nutr 82, 1308-1319.

88. Waterland RA, Travisano M, Tahiliani KG, et al. (2008) Methyl donor supplementation prevents transgenerational amplification of obesity. Int J Obes (Lond) 32, $1373-1379$.

89. Milagro FI, Campion J, Garcia-Diaz DF, et al. (2009) High fat diet-induced obesity modifies the methylation pattern of leptin promoter in rats. J Physiol Biochem $\mathbf{6 5}$ $1-9$. 
90. Thornburg KL, Shannon J, Thuillier P, et al. (2010) In utero life and epigenetic predisposition for disease. Adv Genet 71, 57-78.

91. Michels KB \& Xue F (2006) Role of birthweight in the etiology of breast cancer. Int J Cancer 119, 2007-2025.

92. Malin AS, Qi D, Shu XO, et al. (2003) Intake of fruits, vegetables and selected micronutrients in relation to the risk of breast cancer. Int J Cancer 105, 413-418.

93. Bessaoud F, Daures JP \& Gerber M (2008) Dietary factors and breast cancer risk: a case control study among a population in Southern France. Nutr Cancer 60, $177-187$.

94. Mattisson I, Wirfalt E, Johansson U, et al. (2004) Intakes of plant foods, fibre and fat and risk of breast cancer - a prospective study in the Malmo Diet and Cancer cohort. $\mathrm{Br} \mathrm{J}$ Cancer 90, 122-127.

95. Agurs-Collins T, Rosenberg L, Makambi K, et al. (2009) Dietary patterns and breast cancer risk in women participating in the Black Women's Health Study. Am J Clin Nutr 90 , $621-628$.

96. Sieri S, Krogh V, Bolelli G, et al. (2009) Sex hormone levels, breast cancer risk, and cancer receptor status in postmenopausal women: the ORDET cohort. Cancer Epidemiol Biomarkers Prev 18, 169-176.

97. Terry P, Suzuki R, Hu FB, et al. (2001) A prospective study of major dietary patterns and the risk of breast cancer. Cancer Epidemiol Biomarkers Prev 10, 1281-1285.

98. Adebamowo CA, Hu FB, Cho E, et al. (2005) Dietary patterns and the risk of breast cancer. Ann Epidemiol 15, 789-795.

99. Gonzalez CA \& Riboli E (2010) Diet and cancer prevention: contributions from the European Prospective Investigation into Cancer and Nutrition (EPIC) study. Eur J Cancer 46, $2555-2562$

100. van Gils CH, Peeters PH, Bueno-de-Mesquita HB, et al. (2005) Consumption of vegetables and fruits and risk of breast cancer. JAMA 293, 183-193.

101. Brennan SF, Cantwell MM, Cardwell CR, et al. (2010) Dietary patterns and breast cancer risk: a systematic review and meta-analysis. Am J Clin Nutr 91, 1294-1302.

102. Smith-Warner SA, Spiegelman D, Yaun SS, et al. (2001) Intake of fruits and vegetables and risk of breast cancer: a pooled analysis of cohort studies. JAMA 285, 769-776.

103. Sieri S, Krogh V, Pala V, et al. (2004) Dietary patterns and risk of breast cancer in the ORDET cohort. Cancer Epidemiol Biomarkers Prev 13, 567-572.

104. Cottet V, Touvier M, Fournier A, et al. (2009) Postmenopausal breast cancer risk and dietary patterns in the E3N-EPIC prospective cohort study. Am J Epidemiol 170, 1257-1267.

105. Lissowska J, Gaudet MM, Brinton LA, et al. (2008) Intake of fruits, and vegetables in relation to breast cancer risk by hormone receptor status. Breast Cancer Res Treat 107, 113-117.

106. Olsen A, Tjonneland A, Thomsen BL, et al. (2003) Fruits and vegetables intake differentially affects estrogen receptor negative and positive breast cancer incidence rates. J Nutr 133, 2342-2347.

107. Fung TT, Hu FB, McCullough ML, et al. (2006) Diet quality is associated with the risk of estrogen receptor-negative breast cancer in postmenopausal women. J Nutr 136, $466-472$.

108. Edefonti V, Decarli A, La Vecchia C, et al. (2008) Nutrient dietary patterns and the risk of breast and ovarian cancers Int J Cancer 122, 609-613.

109. de Stefani E, Deneo-Pellegrini H, Boffetta P, et al. (2009) Dietary patterns and risk of cancer: a factor analysis in Uruguay. Int J Cancer 124, 1391-1397.
110. Cui X, Dai Q, Tseng M, et al. (2007) Dietary patterns and breast cancer risk in the Shanghai Breast Cancer Study. Cancer Epidemiol Biomarkers Prev 16, 1443-1448.

111. Murtaugh MA, Sweeney C, Giuliano AR, et al. (2008) Diet patterns and breast cancer risk in Hispanic and non-Hispanic white women: the Four-Corners Breast Cancer Study. Am J Clin Nutr 87, 978-984.

112. Hirose K, Matsuo K, Iwata H, et al. (2007) Dietary patterns and the risk of breast cancer in Japanese women. Cancer Sci 98, 1431-1438.

113. Larsson SC, Bergkvist L \& Wolk A (2009) Long-term meat intake and risk of breast cancer by oestrogen and progesterone receptor status in a cohort of Swedish women. Eur I Cancer 45, 3042-3046.

114. Steinmetz KA \& Potter JD (1996) Vegetables, fruit, and cancer prevention: a review. J Am Diet Assoc 96, 1027-1039.

115. Batra S, Sahu RP, Kandala PK, et al. (2010) Benzyl isothiocyanate-mediated inhibition of histone deacetylase leads to NF-кB turnoff in human pancreatic carcinoma cells. Mol Cancer Ther 9, 1596-1608.

116. Prentice RL, Caan B, Chlebowski RT, et al. (2006) Low-fat dietary pattern and risk of invasive breast cancer: the Women's Health Initiative Randomized Controlled Dietary Modification Trial. JAMA 295, 629-642.

117. Martin LJ, Li Q, Melnichouk O, et al. (2011) A randomized trial of dietary intervention for breast cancer prevention. Cancer Res 71, 123-133.

118. Geisel J, Schorr H, Bodis M, et al. (2005) The vegetarian lifestyle and DNA methylation. Clin Chem Lab Med $\mathbf{4 3}$, $1164-1169$.

119. Lillycrop KA, Phillips ES, Torrens C, et al. (2008) Feeding pregnant rats a protein-restricted diet persistently alters the methylation of specific cytosines in the hepatic PPAR $\alpha$ promoter of the offspring. BrJ Nutr 100, $278-282$

120. Mathers JC \& McKay JA (2009) Epigenetics - potential contribution to fetal programming. Adv Exp Med Biol 646, 119-123.

121. Wu AH, Yu MC, Tseng CC, et al. (2008) Epidemiology of soy exposures and breast cancer risk. Br J Cancer 98, 9-14.

122. Messina M, McCaskill-Stevens W \& Lampe JW (2006) Addressing the soy and breast cancer relationship: review, commentary, and workshop proceedings. J Natl Cancer Inst 98, 1275-1284.

123. Wu AH, Ziegler RG, Nomura AM, et al. (1998) Soy intake and risk of breast cancer in Asians and Asian Americans. Am J Clin Nutr 68, 1437S-1443S.

124. Henderson BE \& Bernstein L (1991) The international variation in breast cancer rates: an epidemiological assessment. Breast Cancer Res Treat 18, Suppl. 1, S11-S17.

125. Ziegler RG, Hoover RN, Pike MC, et al. (1993) Migration patterns and breast cancer risk in Asian-American women. J Natl Cancer Inst 85, 1819-1827.

126. Trock BJ, Hilakivi-Clarke L \& Clarke R (2006) Meta-analysis of soy intake and breast cancer risk. J Natl Cancer Inst $\mathbf{9 8}$, 459-471.

127. Korde LA, Wu AH, Fears T, et al. (2009) Childhood soy intake and breast cancer risk in Asian American women. Cancer Epidemiol Biomarkers Prev 18, 1050-1059.

128. Thanos J, Cotterchio M, Boucher BA, et al. (2006) Adolescent dietary phytoestrogen intake and breast cancer risk (Canada). Cancer Causes Control 17, 1253-1261.

129. Shu XO, Jin F, Dai Q, et al. (2001) Soyfood intake during adolescence and subsequent risk of breast cancer among Chinese women. Cancer Epidemiol Biomarkers Prev 10, 483-488. 
130. Dong JY \& Qin LQ (2011) Soy isoflavones consumption and risk of breast cancer incidence or recurrence: a meta-analysis of prospective studies. Breast Cancer Res Treat 125, $315-323$.

131. Lamartiniere CA, Moore JB, Brown NM, et al. (1995) Genistein suppresses mammary cancer in rats. Carcinogenesis 16, 2833-2840.

132. Barnes S, Peterson TG \& Coward L (1995) Rationale for the use of genistein-containing soy matrices in chemoprevention trials for breast and prostate cancer. J Cell Biochem Suppl 22, 181-187.

133. Barnes S (1997) The chemopreventive properties of soy isoflavonoids in animal models of breast cancer. Breast Cancer Res Treat 46, 169-179.

134. Constantinou AI, Mehta RG \& Vaughan A (1996) Inhibition of N-methyl-N-nitrosourea-induced mammary tumors in rats by the soybean isoflavones. Anticancer Res 16, 3293-3298.

135. Constantinou AI, White BE, Tonetti D, et al. (2005) The soy isoflavone daidzein improves the capacity of tamoxifen to prevent mammary tumours. Eur J Cancer 41, 647-654.

136. Constantinou AI, Lantvit D, Hawthorne M, et al. (2001) Chemopreventive effects of soy protein and purified soy isoflavones on DMBA-induced mammary tumors in female Sprague-Dawley rats. Nutr Cancer 41, 75-81.

137. Gotoh T, Yamada K, Yin H, et al. (1998) Chemoprevention of $\mathrm{N}$-nitroso-N-methylurea-induced rat mammary carcinogenesis by soy foods or biochanin A. Jpn J Cancer Res 89, 137-142.

138. Lamartiniere CA, Cotroneo MS, Fritz WA, et al. (2002) Genistein chemoprevention: timing and mechanisms of action in murine mammary and prostate. J Nutr 132, 552S-558S.

139. Lamartiniere CA, Wang J, Smith-Johnson M, et al. (2002) Daidzein: bioavailability, potential for reproductive toxicity, and breast cancer chemoprevention in female rats. Toxicol Sci 65, 228-238.

140. Hsieh CY, Santell RC, Haslam SZ, et al. (1998) Estrogenic effects of genistein on the growth of estrogen receptorpositive human breast cancer (MCF-7) cells in vitro and in vivo. Cancer Res 58, 3833-3838.

141. Cohen LA, Zhao Z, Pittman B, et al. (2000) Effect of intact and isoflavone-depleted soy protein on NMU-induced rat mammary tumorigenesis. Carcinogenesis 21, 929-935.

142. Wood CE, Kaplan JR, Stute P, et al. (2006) Effects of soy on the mammary glands of premenopausal female monkeys. Fertil Steril 85, Suppl. 1, 1179-1186.

143. Kim H, Hall P, Smith M, et al. (2004) Chemoprevention by grape seed extract and genistein in carcinogen-induced mammary cancer in rats is diet dependent. J Nutr 134, 3445S-3452S.

144. Stedman L, Nickel KP, Castillo SS, et al. (2003) 1,25-dihydroxyvitamin D inhibits vitamin E succinate-induced apoptosis in C3H10T1/2 cells but not Harvey ras-transfected cells. Nutr Cancer 45, 93-100.

145. de Souza PL, Russell PJ, Kearsley JH, et al. (2010) Clinical pharmacology of isoflavones and its relevance for potential prevention of prostate cancer. Nutr Rev $\mathbf{6 8}, 542-555$.

146. Pavese JM, Farmer RL \& Bergan RC (2010) Inhibition of cancer cell invasion and metastasis by genistein. Cancer Metastasis Rev 29, 465-482.

147. Hooper L, Madhavan G, Tice JA, et al. (2010) Effects of isoflavones on breast density in pre- and post-menopausal women: a systematic review and meta-analysis of randomized controlled trials. Hum Reprod Update 16, 745-760.

148. Maskarinec G, Verheus M, Steinberg FM, et al. (2009) Various doses of soy isoflavones do not modify mammographic density in postmenopausal women. $J$ Nutr 139, 981-986.

149. Verheus $\mathrm{M}$, van Gils $\mathrm{CH}$, Kreijkamp-Kaspers S, et al. (2008) Soy protein containing isoflavones and mammographic density in a randomized controlled trial in postmenopausal women. Cancer Epidemiol Biomarkers Prev 17, 2632-2638.

150. Powles TJ, Howell A, Evans DG, et al. (2008) Red clover isoflavones are safe and well tolerated in women with a family history of breast cancer. Menopause Int 14, 6-12.

151. Maskarinec G, Takata Y, Franke AA, et al. (2004) A 2-year soy intervention in premenopausal women does not change mammographic densities. J Nutr 134, 3089-3094.

152. Hilakivi-Clarke L, Cho E, Raygada M, et al. (1997) Alterations in mammary gland development following neonatal exposure to estradiol, transforming growth factor $\alpha$, and estrogen receptor antagonist ICI 182,780. J Cell Physiol 170, 279-289.

153. Hilakivi-Clarke L, Onojafe I, Raygada M, et al. (1999) Prepubertal exposure to zearalenone or genistein reduces mammary tumorigenesis. Br J Cancer 80, 1682-1688.

154. Hilakivi-Clarke L, Cho E, Onojafe I, et al. (1999) Maternal exposure to genistein during pregnancy increases carcinogen-induced mammary tumorigenesis in female rat offspring. Oncol Rep 6, 1089-1095.

155. Petersen OW \& Polyak K (2010) Stem cells in the human breast. Cold Spring Harb Perspect Biol 2, a003160.

156. Dolinoy DC, Weidman JR, Waterland RA, et al. (2006) Maternal genistein alters coat color and protects Avy mouse offspring from obesity by modifying the fetal epigenome. Environ Health Perspect 114, 567-572.

157. Dolinoy DC, Huang D \& Jirtle RL (2007) Maternal nutrient supplementation counteracts bisphenol A-induced DNA hypomethylation in early development. Proc Natl Acad Sci U S A 104, 13056-13061.

158. Qin W, Zhu W, Shi H, et al. (2009) Soy isoflavones have an antiestrogenic effect and alter mammary promoter hypermethylation in healthy premenopausal women. Nutr Cancer 61, 238-244.

159. Berner C, Aumuller E, Gnauck A, et al. (2010) Epigenetic control of estrogen receptor expression and tumor suppressor genes is modulated by bioactive food compounds. Ann Nutr Metab 57, 183-189.

160. Kabat GC, Kim M, Shikany JM, et al. (2010) Alcohol consumption and risk of ductal carcinoma in situ of the breast in a cohort of postmenopausal women. Cancer Epidemiol Biomarkers Prev 19, 2066-2072.

161. Engeset D, Dyachenko A, Ciampi A, et al. (2009) Dietary patterns and risk of cancer of various sites in the Norwegian European Prospective Investigation into Cancer and Nutrition cohort: the Norwegian Women and Cancer study. Eur J Cancer Prev 18, 69-75.

162. Smith-Warner SA, Spiegelman D, Yaun SS, et al. (1998) Alcohol and breast cancer in women: a pooled analysis of cohort studies. JAMA 279, 535-540.

163. Viel JF, Perarnau JM, Challier B, et al. (1997) Alcoholic calories, red wine consumption and breast cancer among premenopausal women. Eur J Epidemiol 13, 639-643.

164. Zhang SM, Lee IM, Manson JE, et al. (2007) Alcohol consumption and breast cancer risk in the Women's Health Study. Am J Epidemiol 165, 667-676.

165. Vachon CM, Kuni CC, Anderson K, et al. (2000) Association of mammographically defined percent breast density with epidemiologic risk factors for breast cancer (United States). Cancer Causes Control 11, 653-662.

166. Newcomb PA, Nichols HB, Beasley JM, et al. (2009) No difference between red wine or white wine consumption 
and breast cancer risk. Cancer Epidemiol Biomarkers Prev 18, 1007-1010.

167. Berstad P, Ma H, Bernstein L, et al. (2008) Alcohol intake and breast cancer risk among young women. Breast Cancer Res Treat 108, 113-120.

168. Ellison RC, Zhang Y, McLennan CE, et al. (2001) Exploring the relation of alcohol consumption to risk of breast cancer. Am J Epidemiol 154, 740-747.

169. Key J, Hodgson S, Omar RZ, et al. (2006) Meta-analysis of studies of alcohol and breast cancer with consideration of the methodological issues. Cancer Causes Control 17, $759-770$.

170. Tjonneland A, Christensen J, Olsen A, et al. (2007) Alcohol intake and breast cancer risk: the European Prospective Investigation into Cancer and Nutrition (EPIC). Cancer Causes Control 18, 361-373.

171. Lew JQ, Freedman ND, Leitzmann MF, et al. (2009) Alcohol and risk of breast cancer by histologic type and hormone receptor status in postmenopausal women: the NIH-AARP Diet and Health Study. Am J Epidemiol 170, 308-317.

172. Poschl G \& Seitz HK (2004) Alcohol and cancer. Alcohol Alcohol 39, 155-165.

173. Boffetta P \& Hashibe M (2006) Alcohol and cancer. Lancet Oncol 7, 149-156.

174. Seitz HK \& Stickel F (2007) Molecular mechanisms of alcohol-mediated carcinogenesis. Nat Rev Cancer 7, 599-612.

175. Reichman ME, Judd JT, Longcope C, et al. (1993) Effects of alcohol consumption on plasma and urinary hormone concentrations in premenopausal women. $J$ Natl Cancer Inst 85, $722-727$.

176. Ginsburg ES, Walsh BW, Gao X, et al. (1995) The effect of acute ethanol ingestion on estrogen levels in postmenopausal women using transdermal estradiol. J Soc Gynecol Investig 2, 26-29.

177. Brooks PJ (1997) DNA damage, DNA repair, and alcohol toxicity - a review. Alcobol Clin Exp Res 21, 1073-1082.

178. Christensen BC, Kelsey KT, Zheng S, et al. (2010) Breast cancer DNA methylation profiles are associated with tumor size and alcohol and folate intake. PLoS Genet $\mathbf{6}$, e1001043.

179. Hursting SD, Thornquist M \& Henderson MM (1990) Types of dietary fat and the incidence of cancer at five sites. Prev Med 19, 242-253

180. Armstrong B \& Doll R (1975) Environmental factors and cancer incidence and mortality in different countries, with special reference to dietary practices. Int $J$ Cancer $\mathbf{1 5}$, 617-631.

181. Lea AJ (1966) Dietary factors associated with death-rates from certain neoplasms in man. Lancet ii, 332-333.

182. Rose DP, Boyar AP \& Wynder EL (1986) International comparisons of mortality rates for cancer of the breast, ovary, prostate, and colon, and per capita food consumption. Cancer 58, 2363-2371.

183. Howe GR, Hirohata T, Hislop TG, et al. (1990) Dietary factors and risk of breast cancer: combined analysis of 12 case-control studies. J Natl Cancer Inst 82, 561-569.

184. Smith-Warner SA, Spiegelman D, Adami HO, et al. (2001) Types of dietary fat and breast cancer: a pooled analysis of cohort studies. Int J Cancer 92, 767-774.

185. Willett WC (1990) Epidemiologic studies of diet and cancer. Prog Clin Biol Res 346, 159-168.

186. Willett WC, Hunter DJ, Stampfer MJ, et al. (1992) Dietary fat and fiber in relation to risk of breast cancer. An 8-year follow-up. JAMA 268, 2037-2044.
187. Schulz M, Hoffmann K, Weikert C, et al. (2008) Identification of a dietary pattern characterized by high-fat food choices associated with increased risk of breast cancer: the European Prospective Investigation into Cancer and Nutrition (EPIC)-Potsdam Study. Br J Nutr 100, 942-946.

188. Alexander DD, Morimoto LM, Mink PJ, et al. (2010) A review and meta-analysis of red and processed meat consumption and breast cancer. Nutr Res Rev 23, 349-365.

189. Bougnoux P, Hajjaji N \& Couet C (2008) The lipidome as a composite biomarker of the modifiable part of the risk of breast cancer. Prostaglandins Leukot Essent Fatty Acids 79, 93-96.

190. Chajes V, Thiebaut AC, Rotival M, et al. (2008) Association between serum trans-monounsaturated fatty acids and breast cancer risk in the E3N-EPIC Study. Am J Epidemiol 167, 1312-1320.

191. Kim EH, Willett WC, Colditz GA, et al. (2006) Dietary fat and risk of postmenopausal breast cancer in a 20 -year follow-up. Am J Epidemiol 164, 990-997.

192. Linos E, Willett WC, Cho E, et al. (2010) Adolescent diet in relation to breast cancer risk among premenopausal women. Cancer Epidemiol Biomarkers Prev 19, 689-696.

193. Fay MP \& Freedman LS (1997) Meta-analyses of dietary fats and mammary neoplasms in rodent experiments. Breast Cancer Res Treat 46, 215-223.

194. Freedman LS, Clifford C \& Messina M (1990) Analysis of dietary fat, calories, body weight, and the development of mammary tumors in rats and mice: a review. Cancer Res 50, 5710-5719.

195. Welsch CW, House JL, Herr BL, et al. (1990) Enhancement of mammary carcinogenesis by high levels of dietary fat: a phenomenon dependent on ad libitum feeding. I Natl Cancer Inst 82, 1615-1620.

196. Welsch CW (1992) Dietary fat, calories, and mammary gland tumorigenesis. Adv Exp Med Biol 322, 203-222.

197. Kritchevsky D, Weber MM \& Klurfeld DM (1984) Dietary fat versus caloric content in initiation and promotion of 7,12dimethylbenz $(a)$ anthracene-induced mammary tumorigenesis in rats. Cancer Res 44, 3174-3177.

198. Klurfeld DM, Weber MM \& Kritchevsky D (1987) Inhibition of chemically induced mammary and colon tumor promotion by caloric restriction in rats fed increased dietary fat. Cancer Res 47, 2759-2762.

199. Woutersen RA, Appel MJ, Van Garderen-Hoetmer A, et al. (1999) Dietary fat and carcinogenesis. Mutat Res 443, 111-127.

200. Chapkin RS, Wang N, Fan YY, et al. (2008) Docosahexaenoic acid alters the size and distribution of cell surface microdomains. Biochim Biophys Acta 1778, 466-471.

201. Simopoulos AP (2010) Genetic variants in the metabolism of omega- 6 and omega- 3 fatty acids: their role in the determination of nutritional requirements and chronic disease risk. Exp Biol Med (Maywood) 235, 785-795.

202. Larsson SC, Kumlin M, Ingelman-Sundberg M, et al. (2004) Dietary long-chain $n-3$ fatty acids for the prevention of cancer: a review of potential mechanisms. Am J Clin Nutr 79, 935-945.

203. de Assis S, Khan G \& Hilakivi-Clarke L (2006) High birth weight increases mammary tumorigenesis in rats. Int $J$ Cancer 119, 1537-1546.

204. Vucetic Z, Kimmel J, Totoki K, et al. (2010) Maternal high-fat diet alters methylation and gene expression of dopamine and opioid-related genes. Endocrinology 151, 4756-4764.

205. Yenbutr P, Hilakivi-Clarke L \& Passaniti A (1998) Hypomethylation of an exon I estrogen receptor CpG 
island in spontaneous and carcinogen-induced mammary tumorigenesis in the rat. Mech Ageing Dev 106, 93-102.

206. Mahoney MC, Bevers T, Linos E, et al. (2008) Opportunities and strategies for breast cancer prevention through risk reduction. CA Cancer J Clin 58, 347-371.

207. Romieu I, Lazcano-Ponce E, Sanchez-Zamorano LM, et al. (2004) Carbohydrates and the risk of breast cancer among Mexican women. Cancer Epidemiol Biomarkers Prev 13, $1283-1289$

208. Gomez LM, Hernandez-Prado B, Morales MC, et al. (2009) Physical activity and overweight/obesity in adult Mexican population: the Mexican National Health and Nutrition Survey 2006. Salud Publica Mex 51, Suppl. 4, S621-S629.

209. Frazier AL, Li L, Cho E, et al. (2004) Adolescent diet and risk of breast cancer. Cancer Causes Control 15, 73-82.

210. Larsson SC, Bergkvist L \& Wolk A (2009) Glycemic load, glycemic index and breast cancer risk in a prospective cohort of Swedish women. Int J Cancer 125, 153-157.

211. Lajous M, Boutron-Ruault MC, Fabre A, et al. (2008) Carbohydrate intake, glycemic index, glycemic load, and risk of postmenopausal breast cancer in a prospective study of French women. Am J Clin Nutr 87, 1384-1391.

212. Nielsen TG, Olsen A, Christensen J, et al. (2005) Dietary carbohydrate intake is not associated with the breast cancer incidence rate ratio in postmenopausal Danish women. J Nutr 135, 124-128.

213. Yanochko GM \& Eckhart W (2006) Type I insulin-like growth factor receptor over-expression induces proliferation and anti-apoptotic signaling in a three-dimensional culture model of breast epithelial cells. Breast Cancer Res 8, R18.

214. Key TJ, Appleby PN, Reeves GK, et al. (2010) Insulin-like growth factor 1 (IGF1), IGF binding protein 3 (IGFBP3), and breast cancer risk: pooled individual data analysis of 17 prospective studies. Lancet Oncol 11, 530-542.

215. Lewis SJ, Harbord RM, Harris R, et al. (2006) Meta-analyses of observational and genetic association studies of folate intakes or levels and breast cancer risk. J Natl Cancer Inst 98, 1607-1622.

216. Zhang S, Hunter DJ, Hankinson SE, et al. (1999) A prospective study of folate intake and the risk of breast cancer. JAMA 281, 1632-1637.

217. Larsson SC, Giovannucci E \& Wolk A (2007) Folate and risk of breast cancer: a meta-analysis. J Natl Cancer Inst 99, $64-76$.

218. Mason JB \& Choi SW (2000) Folate and carcinogenesis: developing a unifying hypothesis. Adv Enzyme Regul 40, 127-141.

219. Stolzenberg-Solomon RZ, Chang SC \& Leitzmann MF (2006) Folate intake, alcohol use, and postmenopausal breast cancer risk in the Prostate, Lung, Colorectal, and Ovarian Cancer Screening Trial. Am J Clin Nutr 83, 895-904.

220. Chen J, Gammon MD, Chan W, et al. (2005) One-carbon metabolism, MTHFR polymorphisms, and risk of breast cancer. Cancer Res 65, 1606-1614.

221. Lajous $\mathrm{M}$, Lazcano-Ponce $\mathrm{E}$, Hernandez-Avila $\mathrm{M}$, et al. (2006) Vitamin $B_{6}$, and vitamin $B_{12}$ intake and the risk of breast cancer among Mexican women. Cancer Epidemiol Biomarkers Prev 15, 443-448.

222. Levi F, Pasche C, Lucchini F, et al. (2001) Dietary intake of selected micronutrients and breast-cancer risk. Int J Cancer 91, 260-263.

223. Negri E, La Vecchia C \& Franceschi S (2000) Re: dietary folate consumption and breast cancer risk. J Natl Cancer Inst 92, 1270-1271.
224. Ronco A, de Stefani E, Boffetta P, et al. (1999) Vegetables, fruits, and related nutrients and risk of breast cancer: a case-control study in Uruguay. Nutr Cancer 35, 111-119.

225. Shrubsole MJ, Gao YT, Cai Q, et al. (2004) MTHFR polymorphisms, dietary folate intake, and breast cancer risk: results from the Shanghai Breast Cancer Study. Cancer Epidemiol Biomarkers Prev 13, 190-196.

226. Lajous M, Romieu I, Sabia S, et al. (2006) Folate, vitamin $B_{12}$ and postmenopausal breast cancer in a prospective study of French women. Cancer Causes Control 17, 1209-1213.

227. Shrubsole MJ, Jin F, Dai Q, et al. (2001) Dietary folate intake and breast cancer risk: results from the Shanghai Breast Cancer Study. Cancer Res 61, 7136-7141.

228. Zhang SM, Willett WC, Selhub J, et al. (2003) Plasma folate, vitamin $\mathrm{B}_{6}$, vitamin $\mathrm{B}_{12}$, homocysteine, and risk of breast cancer. J Natl Cancer Inst 95, 373-380.

229. Ericson U, Borgquist S, Ivarsson MI, et al. (2010) Plasma folate concentrations are positively associated with risk of estrogen receptor $\beta$ negative breast cancer in a Swedish nested case control study. J Nutr 140, 1661-1668.

230. Kim YI (2005) Nutritional epigenetics: impact of folate deficiency on DNA methylation and colon cancer susceptibility. J Nutr 135, 2703-2709.

231. Kim YI (2004) Will mandatory folic acid fortification prevent or promote cancer? Am J Clin Nutr 80, 1123-1128.

232. Choi SW \& Mason JB (2000) Folate and carcinogenesis: an integrated scheme. J Nutr 130, 129-132.

233. Kotsopoulos J, Medline A, Renlund R, et al. (2005) Effects of dietary folate on the development and progression of mammary tumors in rats. Carcinogenesis $\mathbf{2 6}$ 1603-1612.

234. Kotsopoulos J, Sohn KJ, Martin R, et al. (2003) Dietary folate deficiency suppresses $N$-methyl- $N$-nitrosourea-induced mammary tumorigenesis in rats. Carcinogenesis 24, 937-944.

235. Baggott JE, Vaughn WH, Juliana MM, et al. (1992) Effects of folate deficiency and supplementation on methylnitrosourea-induced rat mammary tumors. J Natl Cancer Inst 84, $1740-1744$.

236. Mason JB \& Choi SW (2005) Effects of alcohol on folate metabolism: implications for carcinogenesis. Alcohol 35, $235-241$.

237. Lin J, Lee IM, Cook NR, et al. (2008) Plasma folate, vitamin B-6, vitamin B-12, and risk of breast cancer in women. Am J Clin Nutr 87, 734-743.

238. Williams KT \& Schalinske KL (2007) New insights into the regulation of methyl group and homocysteine metabolism. J Nutr 137, 311-314.

239. Mehedint MG, Niculescu MD, Craciunescu CN, et al. (2010) Choline deficiency alters global histone methylation and epigenetic marking at the Re1 site of the calbindin 1 gene. FASEB J 24, 184-195.

240. Ly A, Lee H, Chen J, et al. (2011) Effect of maternal and postweaning folic acid supplementation on mammary tumor risk in the offspring. Cancer Res 71, 988-997.

241. Sie KK, Chen J, Sohn KJ, et al. (2009) Folic acid supplementation provided in utero and during lactation reduces the number of terminal end buds of the developing mammary glands in the offspring. Cancer Lett 280, 72-77.

242. Steegers-Theunissen RP, Obermann-Borst SA, Kremer D, et al. (2009) Periconceptional maternal folic acid use of 400 microg per day is related to increased methylation of the IGF2 gene in the very young child. PLoS One 4 , e7845.

243. Lelievre SA (2009) Contributions of extracellular matrix signaling and tissue architecture to nuclear mechanisms and spatial organization of gene expression control. Biochim Biophys Acta 1790, 925-935. 
244. Stempak JM, Sohn KJ, Chiang EP, et al. (2005) Cell and stage of transformation-specific effects of folate deficiency on methionine cycle intermediates and DNA methylation in an in vitro model. Carcinogenesis 26, 981-990.

245. Song J, Medline A, Mason JB, et al. (2000) Effects of dietary folate on intestinal tumorigenesis in the apcMin mouse. Cancer Res 60, 5434-5440.

246. Garland CF, Gorham ED, Mohr SB, et al. (2007) Vitamin D and prevention of breast cancer: pooled analysis. J Steroid Biochem Mol Biol 103, 708-711.

247. Cui Y \& Rohan TE (2006) Vitamin D, calcium, and breast cancer risk: a review. Cancer Epidemiol Biomarkers Prev 15, 1427-1437.

248. Garland FC, Garland CF, Gorham ED, et al. (1990) Geographic variation in breast cancer mortality in the United States: a hypothesis involving exposure to solar radiation. Prev Med 19, 614-622.

249. Lowe LC, Guy M, Mansi JL, et al. (2005) Plasma 25-hydroxy vitamin $\mathrm{D}$ concentrations, vitamin $\mathrm{D}$ receptor genotype and breast cancer risk in a UK Caucasian population. Eur $J$ Cancer 41, 1164-1169.

250. Chen P, Hu P, Xie D, et al. (2010) Meta-analysis of vitamin $\mathrm{D}$, calcium and the prevention of breast cancer. Breast Cancer Res Treat 121, 469-477.

251. Lin J, Manson JE, Lee IM, et al. (2007) Intakes of calcium and vitamin D and breast cancer risk in women. Arch Intern Med 167, 1050-1059.

252. Shin MH, Holmes MD, Hankinson SE, et al. (2002) Intake of dairy products, calcium, and vitamin D and risk of breast cancer. J Natl Cancer Inst 94, 1301-1311.

253. Robien K, Cutler GJ \& Lazovich D (2007) Vitamin D intake and breast cancer risk in postmenopausal women: the Iowa Women's Health Study. Cancer Causes Control 18, 775-782.

254. Blot WJ, Fraumeni JF Jr \& Stone BJ (1977) Geographic patterns of breast cancer in the United States. $J$ Natl Cancer Inst 59, 1407-1411.

255. McCullough ML, Rodriguez C, Diver WR, et al. (2005) Dairy, calcium, and vitamin D intake and postmenopausal breast cancer risk in the Cancer Prevention Study II Nutrition Cohort. Cancer Epidemiol Biomarkers Prev 14, 2898-2904

256. Zierold C, Mings JA \& Deluca HF (2003) Regulation of 25-hydroxyvitamin $\mathrm{D}_{3}$-24-hydroxylase mRNA by 1,25-dihydroxyvitamin $\mathrm{D}_{3}$ and parathyroid hormone. J Cell Biochem $\mathbf{8 8}, 234-237$.

257. Armbrecht HJ, Boltz MA \& Hodam TL (2003) PTH increases renal $25(\mathrm{OH}) \mathrm{D}_{3}-1 \alpha$-hydroxylase $(\mathrm{CYP} 1 \alpha)$ mRNA but not renal $1,25(\mathrm{OH})_{2} \mathrm{D}_{3}$ production in adult rats. Am J Physiol Renal Physiol 284, F1032-F1036.

258. Li J, Byrne ME, Chang E, et al. (2008) 1 $\alpha, 25$-Dihydroxyvitamin D hydroxylase in adipocytes. J Steroid Biochem Mol Biol 112, 122-126.

259. Kemmis CM, Salvador SM, Smith KM, et al. (2006) Human mammary epithelial cells express CYP27B1 and are growth inhibited by 25 -hydroxyvitamin $\mathrm{D}_{3}$, the major circulating form of vitamin $\mathrm{D}_{3}$. J Nutr 136, 887-892.

260. Zehnder D, Bland R, Williams MC, et al. (2001) Extrarenal expression of 25 -hydroxyvitamin $\mathrm{D}_{3}-1 \alpha$-hydroxylase. J Clin Endocrinol Metab 86, 888-894.

261. Norman AW (2008) From vitamin D to hormone D: fundamentals of the vitamin $\mathrm{D}$ endocrine system essential for good health. Am J Clin Nutr 88, 491S-499S.

262. Haussler MR, Haussler CA, Bartik L, et al. (2008) Vitamin D receptor: molecular signaling and actions of nutritional ligands in disease prevention. Nutr Rev 66, S98-S112.
263. Bernardi RJ, Johnson CS, Modzelewski RA, et al. (2002) Antiproliferative effects of $1 \alpha, 25$-dihydroxyvitamin $\mathrm{D}_{3}$ and vitamin $\mathrm{D}$ analogs on tumor-derived endothelial cells. Endocrinology 143, 2508-2514.

264. Wali RK, Baum CL, Bolt MJ, et al. (1992) 1,25-Dihydroxyvitamin D3 inhibits $\mathrm{Na}(+)-\mathrm{H}+$ exchange by stimulating membrane phosphoinositide turnover and increasing cytosolic calcium in CaCo-2 cells. Endocrinology 131, $1125-1133$.

265. Wali RK, Baum CL, Sitrin MD, et al. (1992) Effect of vitamin D status on the rapid actions of 1,25-dihydroxycholecalciferol in rat colonic membranes. Am J Physiol 262, G945-G953.

266. Li W \& Farach-Carson MC (2001) Parathyroid hormonestimulated resorption in calvaria cultured in serum-free medium is enhanced by the calcium-mobilizing activity of 1,25-dihydroxyvitamin $\mathrm{D}_{3}$. Bone 29, 231-235.

267. Norman AW, Okamura WH, Bishop JE, et al. (2002) Update on biological actions of $1 \alpha, 25(\mathrm{OH})_{2}$-vitamin $\mathrm{D}_{3}$ (rapid effects) and 24R,25(OH) $)_{2}$-vitamin $\mathrm{D}_{3}$. Mol Cell Endocrinol 197, $1-13$

268. Matthews D, LaPorta E, Zinser GM, et al. (2010) Genomic vitamin D signaling in breast cancer: insights from animal models and human cells. J Steroid Biochem Mol Biol 121, 362-367.

269. Zinser GM \& Welsh J (2004) Vitamin D receptor status alters mammary gland morphology and tumorigenesis in MMTVneu mice. Carcinogenesis 25, 2361-2372.

270. Zinser GM, Suckow M \& Welsh J (2005) Vitamin D receptor (VDR) ablation alters carcinogen-induced tumorigenesis in mammary gland, epidermis and lymphoid tissues. J Steroid Biochem Mol Biol 97, 153-164.

271. Kurihara N, Fan K, Thaler HT, et al. (2008) Effect of a Western-style diet fortified with increased calcium and vitamin $\mathrm{D}$ on mammary gland of $\mathrm{C} 57 \mathrm{BL} / 6$ mice. $\mathrm{J}$ Med Food 11, 201-206.

272. Jacobson EA, James KA, Newmark HL, et al. (1989) Effects of dietary fat, calcium, and vitamin D on growth and mammary tumorigenesis induced by 7,12-dimethylbenz( $a$ )anthracene in female Sprague-Dawley rats. Cancer Res $\mathbf{4 9}$, 6300-6303.

273. Welsh J (2007) Vitamin D and prevention of breast cancer. Acta Pharmacol Sin 28, 1373-1382.

274. Chlebowski RT, Johnson KC, Kooperberg C, et al. (2008) Calcium plus vitamin D supplementation and the risk of breast cancer. J Natl Cancer Inst 100, 1581-1591.

275. Lappe JM, Travers-Gustafson D, Davies KM, et al. (2007) Vitamin D and calcium supplementation reduces cancer risk: results of a randomized trial. Am J Clin Nutr 85, 1586-1591.

276. Banwell CM, MacCartney DP, Guy M, et al. (2006) Altered nuclear receptor corepressor expression attenuates vitamin D receptor signaling in breast cancer cells. Clin Cancer Res 12, 2004-2013.

277. Kim MS, Fujiki R, Kitagawa $\mathrm{H}$, et al. (2007) $1 \alpha, 25(\mathrm{OH})_{2} \mathrm{D}_{3^{-}}$ induced DNA methylation suppresses the human CYP27B1 gene. Mol Cell Endocrinol 265-266, 168-173.

278. Novakovic B, Sibson M, Ng HK, et al. (2009) Placentaspecific methylation of the vitamin D 24-hydroxylase gene: implications for feedback autoregulation of active vitamin D levels at the fetomaternal interface. J Biol Chem 284, 14838-14848.

279. Luo W, Karpf AR, Deeb KK, et al. (2010) Epigenetic regulation of vitamin D 24-hydroxylase/CYP24A1 in human prostate cancer. Cancer Res 70, 5953-5962.

280. Deeb KK, Luo W, Karpf AR, et al. (2011) Differential vitamin D 24-hydroxylase/CYP24A1 gene promoter methylation in 
endothelium from benign and malignant human prostate. Epigenetics 6, 994-1000.

281. Margolis RN \& Christakos S (2010) The nuclear receptor superfamily of steroid hormones and vitamin D gene regulation. An update. Ann N Y Acad Sci 1192, 208-214.

282. Giovannucci E (1999) Tomatoes, tomato-based products, lycopene, and cancer: review of the epidemiologic literature. J Natl Cancer Inst 91, 317-331.

283. Rohan TE (2001) Invited Commentary: serum carotenoids and breast cancer. Am J Epidemiol 153, 1148-1150.

284. Toniolo P, Van Kappel AL, Akhmedkhanov A, et al. (2001) Serum carotenoids and breast cancer. Am J Epidemiol 153, $1142-1147$

285. Zhang S, Hunter DJ, Forman MR, et al. (1999) Dietary carotenoids and vitamins $\mathrm{A}, \mathrm{C}$, and $\mathrm{E}$ and risk of breast cancer. J Natl Cancer Inst 91, 547-556.

286. Hulten K, Van Kappel AL, Winkvist A, et al. (2001) Carotenoids, $\alpha$-tocopherols, and retinol in plasma and breast cancer risk in northern Sweden. Cancer Causes Control 12, 529-537.

287. Nissen SB, Tjonneland A, Stripp C, et al. (2003) Intake of vitamins $\mathrm{A}, \mathrm{C}$, and $\mathrm{E}$ from diet and supplements and breast cancer in postmenopausal women. Cancer Causes Control 14, 695-704.

288. Wald NJ, Boreham J, Hayward JL, et al. (1984) Plasma retinol, $\beta$-carotene and vitamin $E$ levels in relation to the future risk of breast cancer. BrJ Cancer 49, 321-324.

289. Epplein M, Shvetsov YB, Wilkens LR, et al. (2009) Plasma carotenoids, retinol, and tocopherols and postmenopausal breast cancer risk in the Multiethnic Cohort Study: a nested case-control study. Breast Cancer Res 11, R49.

290. Mignone LI, Giovannucci E, Newcomb PA, et al. (2009) Dietary carotenoids and the risk of invasive breast cancer. Int J Cancer 124, 2929-2937.

291. Sato R, Helzlsouer KJ, Alberg AJ, et al. (2002) Prospective study of carotenoids, tocopherols, and retinoid concentrations and the risk of breast cancer. Cancer Epidemiol Biomarkers Prev 11, 451-457.

292. Kabat GC, Kim M, Adams-Campbell LL, et al. (2009) Longitudinal study of serum carotenoid, retinol, and tocopherol concentrations in relation to breast cancer risk among postmenopausal women. Am J Clin Nutr 90, 162-169.
293. Rabi T \& Bishayee A (2009) Terpenoids and breast cancer chemoprevention. Breast Cancer Res Treat 115, 223-239.

294. Okuno M, Kojima S, Matsushima-Nishiwaki R, et al. (2004) Retinoids in cancer chemoprevention. Curr Cancer Drug Targets 4, 285-298.

295. Black HS (2004) Pro-carcinogenic activity of $\beta$-carotene, a putative systemic photoprotectant. Photochem Photobiol Sci 3, 753-758.

296. Valko M, Izakovic M, Mazur M, et al. (2004) Role of oxygen radicals in DNA damage and cancer incidence. Mol Cell Biochem 266, 37-56.

297. King-Batoon A, Leszczynska JM \& Klein CB (2008) Modulation of gene methylation by genistein or lycopene in breast cancer cells. Environ Mol Mutagen 49, 36-45.

298. Bistulfi G, Pozzi S, Ren M, et al. (2006) A repressive epigenetic domino effect confers susceptibility to breast epithelial cell transformation: implications for predicting breast cancer risk. Cancer Res 66, 10308-10314.

299. Ndiaye M, Kumar R \& Ahmad N (2011) Resveratrol in cancer management: where are we and where we go from here? Ann N Y Acad Sci 1215, 144-149.

300. Koo SH \& Montminy M (2006) In vino veritas: a tale of two sirt1s? Cell 127, 1091-1093.

301. Binda O, Nassif C \& Branton PE (2008) SIRT1 negatively regulates HDAC1-dependent transcriptional repression by the RBP1 family of proteins. Oncogene 27, 3384-3392

302. Miller A, Chen J, Takasuka TE, et al. (2010) Proliferating cell nuclear antigen (PCNA) is required for cell-cycle regulated silent chromatin on replicated and nonreplicated genes. J Biol Chem 285, 35142-35154.

303. Abad PC, Lewis J, Mian IS, et al. (2007) NuMA influences higher order chromatin organization in human mammary epithelium. Mol Biol Cell 18, 348-361.

304. Vasanthi D \& Mishra RK (2008) Epigenetic regulation of genes during development: a conserved theme from flies to mammals. J Genet Genomics 35, 413-429.

305. Plachot C, Chaboub LS, Adissu HA, et al. (2009) Factors necessary to produce basoapical polarity in human glandular epithelium formed in conventional and high-throughput three-dimensional culture: example of the breast epithelium. BMC Biol 7, 77. 